\title{
The Corona Virus Pandemic And Stochastic Growth: Implications For Developed, Developing, And Emerging Economies
}

\author{
Diana Loubaki \\ ISG, Department of Economics, Marien NGouabi University, \\ Brazzaville, Congo Republic
}

Doi:10.19044/esj.2021.v17n21p204

Submitted: 11 December 2020

Accepted: 17 February 2021

Published: 30 June 2021
Copyright 2021 Author(s)

Under Creative Commons BY-NC-ND 4.0 OPEN ACCESS

Cite As:

Loubaki D. (2021). The Corona Virus Pandemic And Stochastic Growth: Implications For Developed, Developing, And Emerging Economies. European Scientific Journal, ESJ, 17(21), 204.

https://doi.org/10.19044/esj.2021.v17n21p204

\begin{abstract}
This article studies the impact of the "coronavirus" on the economy when the growth path follows a stochastic Markov process in a multi countries' exchange context. The methodology used is endogenous growth theory coupled with topology, the fixed point, and the separation theorem for the equilibrium determination through private agents' maximization behaviors. Thereafter, the equilibrium is rendered optimal in the Pareto sense through the linear programming method and the portfolio choice theory used by the social planner. The results found are: First, growth decreases almost everywhere; second, per-capita income increase in contrast. Finally, the conjunction of the whole accelerates convergence and catching-up since the most affected countries are also the richest. As a result, they experience higher economic and social disorders giving credibility to the Solow (1956) marginal productivity that decrease the hypothesis that poor countries grow faster than rich countries. Consequently, the pandemic negative action is an accelerator of the economic retarded countries market-based economy which targets a faster means of achievement.
\end{abstract}


Keywords: Stochastic Growth, The Markov Process, Multi-Countries Growth, Network Connection, Coronavirus, Global Long-Run Growth, The Inverted U-Shape Curve

\section{Introduction}

\section{Motivations of the Analysis \\ Brief Literature of the Article}

This article studies the impact of "the coronavirus" on both economic growth and income inequalities. Since the first component deals with private agents submitted to market, i.e., the equilibrium part, the second part focuses on the social planner duty by looking for the optimality of the equilibrium part. Here, the synthesis made consists of the summary of the whole world in three blocks which are: first the developed countries where per-capita income exceeds 12,000 dollars; second, the emerging countries where per-capita income is located around 1,031 and less than 12,000 dollars; third, the developing countries where per-capita income is less than 1,031 dollars in the sample. The application of the theory built, highlighted by numerical experiments using data observations, show that the virus yields mutations on growth and income everywhere in the network connected countries divided into three blocks. Here, both growth and income suddenly fall everywhere at the beginning of the pandemic event. This is such that in both the developed and the emerging world, growth oscillates and decreases in a cyclical way, whereas income turns out to increase and keeps growing at a constant rate in the developing world after. In contrast, income increases monotonically, respectively, in emerging and in industrialized countries. Therefore, the globalized market is highlighted by a kind of ball of center $x_{0}$ and of radius $r$. Here, $x_{0}$ is the unique stable equilibrium highlighted by $\left(G^{*}, D^{*}\right)=x_{0}$, which thus are cyclical functions where the growth path is stochastic and follows a Markov chain. It is empirically measured by the GDP for $G^{*}$ and deaths' stock $D^{*}$ caused by the virus. Thus, $r$ is the length corresponding to the transition toward the unique market or the growth zone where all the connected countries gravitate (see Figure 0 below for illustration). Indeed, $d\left(x_{0}, r\right)$ is the distance between the advanced and the least advanced countries, specifically those which are in transition toward the market-based economy or the economic growth zone. In this case, it is assumed that $r=r_{i}, i=1,2,3$, and $x_{0}=x_{0}{ }^{1}, x_{0}{ }^{2}, x_{0}{ }^{3}$ and it yields $d\left(x_{0}{ }^{i}, r_{i}\right) \rightarrow d\left(x_{0}, r\right)=B\left(x_{0}, r\right)$, which is the closed ball of center $x_{0}$ and of radius $r$ (see Figure 0 below).

Consequently, this study is inspired by the current world economic context, i.e., the coronavirus, sanitary crisis, that we attempt to model in this article on the basis of the following works. The first is that of Lucas (1988) where human capital initiated by Becker (1964) and Shultz (1960) is introduced in growth theory in order to explain what causes the existing 
heterogeneities in levels and rate of growth among countries since Solow (1956) fail to explain that empirical fact and concludes on convergence among countries in the long-run. The second works series in which our article is based are Lucas (2000) and Lucas (2009), which investigate initial divergence and subsequent convergence of income across countries in a multi-country version of a simple economic growth model. Third, Linder and Strulik (2018), a multicountries growth model where connected countries exchange knowledge, addressed several new facts which are: the increasing flow of ideas through globalization, accelerating growth rates across-country variations of growth rates that increase with distance from the technology frontier, large income and TFP differences across countries, as well as per-capita human capital increase throughout the world. Therefore, the economic take-off and subsequent growth are endogenously explained and understood by the increasing diffusion of knowledge around the world. Indeed, as the summary of the whole quoted works, our work follows the multi-countries growth literature where integrated economies operate through a network, making spillovers emerge from exchanges. Thereafter, this boosts the economy and is finally expected to tend toward the more advanced economies level. However, the previous articles don't take account of random sudden negative shocks which is directly transmitted to other countries, i.e., negative transmission risks inside the network other than financial disturbances are not studied in the growth models yet. This we attempt to do here through the coronavirus pandemic viewed in China first and transmitted to the whole world due to the existing links among countries through networks. Indeed, the research question addressed by this article is on the impact of the coronavirus on growth and income in the whole networks connected countries. However, the preliminary universal remedy that proposed to eradicate the pandemic are networks temporary break and ensuring social distancing among inhabitants of the same country as well as around the world with airports temporary closed. Also, the question on how to leave the unique equilibrium successfully emerges when several of them exist with the international cooperation policy intervention.

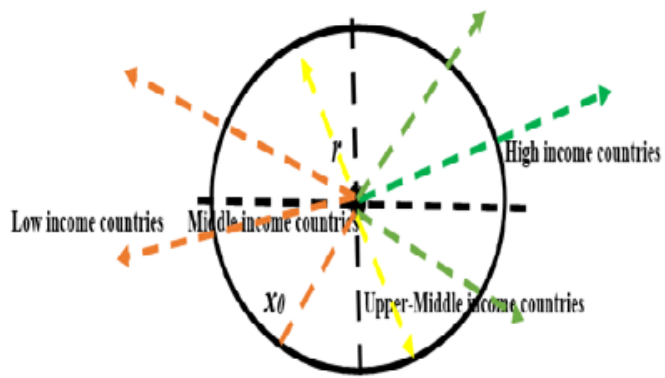

Figure $\mathbf{0}$. The globalized market, a ball of center $x_{0}$ and of radius $r$ 
The other works in the small existing literature on networks in the context of economic growth are described below. First, Cavalcanti and Giannitsarou (2012) investigate learning externalities between households or schooling in simple networks and focus on convergence behavior. Second, Fogli and Veldkamp (2012) provide a study on the role of network connectivity for the diffusion of knowledge and diseases. This is close to our study that focuses on the coronavirus but more specific than their work. Third, Lindner and Strulik (2013) investigate how economic development is affected by globalization conceptualized as an evolving network, i.e., how decreasing local connectivity affects occupational choice and investment behavior through eroding trust and trustworthiness. In contrast, in our article, countries are gathered such as blocks sharing the same economic characteristics connected through a network for knowledge exchange purposes. Thereafter, negative externalities such as sudden shocks are shared among all the partners and then all the countries connected to the one which holds the shock initially faces evictions based on the results expected. Focusing on the coronavirus, its negative impact on growth sustainability is difficult achieve. This ruled out standard conventions on growth and income as one of the concerns of this study. Thus, the theory provided in this article deals with preventions using empirical data after having provided analytical examples of the theory built step by step. Numerical experiments of the theoretical results are conducted by dividing the world economy into three economic performance blocks where the theory is built upon the private agents' behaviors for the equilibrium first and the social planner for the optimality of the equilibrium after. Finally, the globalized economy summarizes the whole agents' behaviors as well as the countries' blocks characteristics. Since the pandemic eradication means sustainable growth establishment, which is in conformity to the economic literature, sustainability is similar to the inverted U-shape curve emergence which was initially provided by Kuznets (1957) and introduced in environmental economics in the 1990s. Thus, it is used as an economic policy success condition where the fixed-point existence, announcing the unique equilibrium back, is the concern of countries which when open: yield multiple equilibria for globalization purpose; needs to converge toward a unique equilibrium symbolized by a zone delimitation similar to a ball centered on the unique equilibrium shared by the whole world economic countries blocks where they gravitate; displays a larger growth zone where all the connected countries' economic growth paths are located around that locus and all neighbors in the exchange. However, the available multi-country's growth literature mostly focuses on the question of whether and how, initially, different countries converge sometimes as well as why they diverge (Linders \& Strulik, 2018). The question of the existing inequalities among the whole countries in the world is the concern of that new growth approach. As shown 
in Table 1 below, SARS-COV2 data source recorded up to $16,037.768$ coronavirus detected cases and 644.785 deaths in July 2020.

Table 1. Brief presentation of the coronavirus shock effect and transmission risk

\begin{tabular}{|c|c|c|c|}
\hline $\begin{array}{c}\text { Coronavirus in } \\
\mathbf{2 0 2 0}\end{array}$ & $\begin{array}{c}\text { INFECTE } \\
\text { D }\end{array}$ & $\begin{array}{c}\text { DEATH } \\
\text { S }\end{array}$ & $\begin{array}{c}\text { RECOVERE } \\
\text { D }\end{array}$ \\
\hline FRANCE & 170,752 & 30,004 & \\
\hline BRAZIL & $1,604,585$ & 64,900 & $9,787,615$ \\
\hline INDIA & 698,233 & 19,703 & 424,928 \\
\hline RUSSIA & 681,251 & 10,261 & 450,750 \\
\hline USA & $2,982,928$ & 132,569 & $1,289,564$ \\
\hline
\end{tabular}

Source: SARS-COV2, Corona Virus

Coronavirus started in Wuhan (China) in the month of January 2020. This has resulted to more than 569, 370 deaths in the whole world in July 2020 (see Figure 1), which necessitates various research to proffer effective solutions to this pandemic. From a political aspect, vaccine is used as prevention measures in contrast to AIDS which, until today, doesn't exist.

The globalized world economy due to the impact of coronavirus yields a unique equilibrium existence highlighted by a ball endowed by a center and a radius, $B\left(x_{0}, r\right)$. This is already invocated above such that the gravitation around the ball leaves and emerge as the new globalized world which, when compares to before, highlights mutations in the theory of economic growth where growth is stochastic. Therefore, this is in contrast to the standard theory where it is stable over time due to financial disturbances caused by asset prices movements absence since the real economy is not the stochastic component. Therefore, current solutions call back the link between medicine and economy already established at the beginning of the year 2000 as the case of obesity (Goel, 2006; Zon-Muysken, 2001; Cutler et al., 2003; Chou et al., 2004) and AIDS (Kremer \& Glennester, 2004; Loubaki, 2012a; Duflo et al., 2018). Finally, there was a breakthrough because medicine science worked on them and yields efficient solutions, for example, antiretroviral drugs for AIDS and stomach surgery for obesity.

Consequently, this article contributes to the coronavirus debate in the context of multi-countries stochastic growth literature interaction with health focused on a sudden shock emergence of a dangerous disease. Thus, this results to a rapid death in contrast to AIDS and obesity as shown in Figure 1.

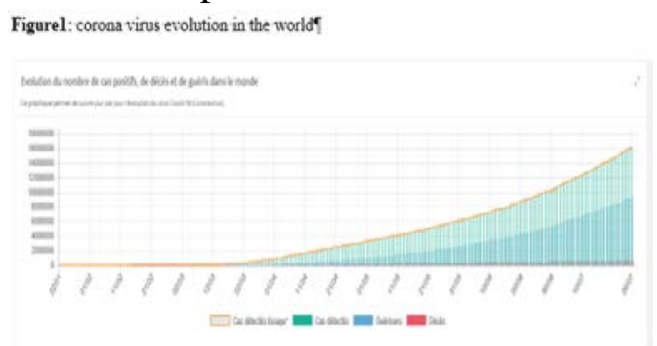

Caption of Figure 1: Yellow line: regression of the detected cases; green box: detected cases recordect: blue box: healed cases recorded; red box: deaths number recordes; $x$ axis represent the years; $y$ axis represent the number of deaths 
Furthermore, private agents' behavior is modeled using mathematical tools, i.e., theorems and lemmas. The social planner enters into the model using a linear programming technique resulting to the inverted U-shape curve (see Figure 2).

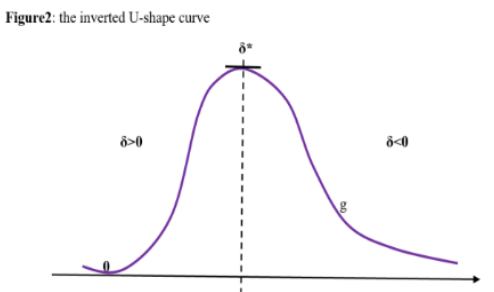

According to Figure 2 ( $x$ axis represents the length of the pandemic evolution and the $y$ axis represents growth evolution), $\delta \epsilon\left[\delta_{1}, \delta^{*}\right]$, the virus curve dynamics gravity, $s_{t+1}=\mathrm{vc}$, is increasing. Thus, $\partial v c / \partial t=\partial s_{t+1} / \partial s_{t}=\delta>0$. The economic policy will be engaged and would keep increasing until the reach of $\delta^{*}$; then after, the virus curve dynamics gravity, $s_{t+1}$, would also decrease, i.e., when $\delta \epsilon\left[\delta^{*}, \delta_{2}\right]$ since now, $\partial s_{t+1} / \partial s_{t}=\delta<0$. This results to sustainable growth and the coronavirus dynamics finally exhibits the inverted U-shape curve. Indeed, since the coronavirus dynamics, $s_{t+1}$, is assimilated to the detection cases according to data observations, $s_{t+1}$ yields multiple equilibria depending on the impact of the pandemic from one place to the other (see Figure 3). Therefore, the unique equilibrium, if it exists, should correspond to the world sanitary crisis stability possibility (see Figure 3).

Figure3: corona virus cases evolution in the world
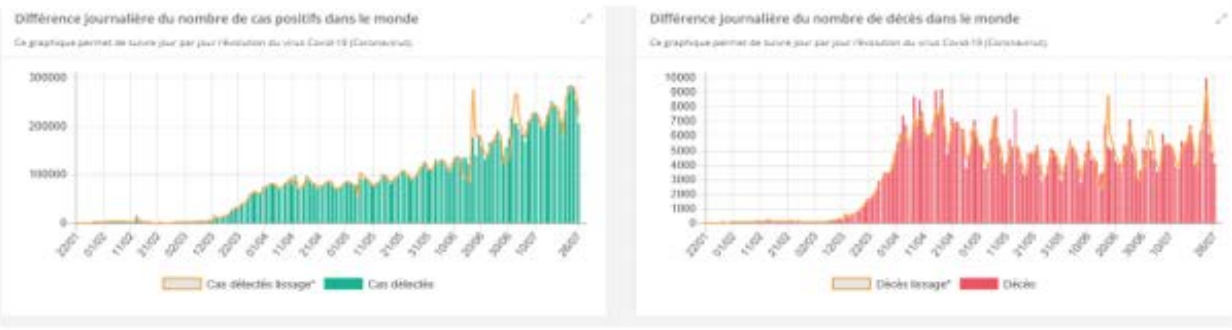

Figure 3 part 3a represents the relationship between dates in $x$ axis and detected sick people number in $y$ axis, whereas $3 b$ represents the relationship between dates ( $x$ axis) and deceased caused by the coronavirus pandemic $(y$ axis). The first part of Figure 3a show-off the detected cases dynamics, $s_{t+1}$, as an increasing curve according to the data observation. Here, the pic provided by data is reached at the date, just before July 27, whereas it emerges the first time at around January 2020 in China and spread all over the whole world. The curve begins to decrease after the date, July 27, after the pic crossed according to data observations display by the first part of Figure 3. The second 
curve of Figure 3b highlights death cases evolution, denoted in this article, $D_{t+1}$ in level or $d_{t+1}=D_{t+1} / D_{t}$ in evolution rate. Here, multiple pics equilibria are highlighted due to heterogeneities of the severity of the virus among different countries of the world. The whole world curve, thus, highlights oscillatory dynamics endowed with several different pics. Indeed, if the curve is viewed in its global plan (or on the average), it begins to decrease after the pic is reached due to the international cooperation policy.

\section{Graphical Presentation of the Problem}

Figures 4 and 5 below summarize the whole world on the space $\mathrm{R}$ where the scale used is an increasing function of the economic performance. Here, the equilibrium of stochastic growth following a Markovian process yields both the existence and the stability of the equilibrium provided by the compact subset of $\mathrm{R}$ in which countries belong since it is a closed and bounded set of R. Therefore, each countries' growth path sequences converges toward at least one limit called the equilibrium. Since the Markovian growth path sequences $\left\{G_{n+1}{ }^{i}\right\}_{n \geq 0, i \epsilon I}$ belongs to the countries' block indexed by $i$ at time $n$, then it converges at least to one limit, $G^{i *}$, because of the compactness of the subset of $\mathrm{R}$ in which they belong and where the limit is located on the boundary of that set. Therefore, since the dynamics of the sequence of the $i$ countries' block, $\left\{G_{n+1}{ }^{i}\right\}_{n \geq 0, i \epsilon}$, possesses a transition probability matrix as stipulated by a closeness according to the standard mathematical theory, and it also possesses a speed component that allows it to move from one place to the other. Thus, this explains how and why some countries grow and some others don't, which is due to technological change growth rate speed. When high, it allows for higher growth and income as proved by numerical experiments, convergence, and catching-up speed making them the least advanced economies where the pandemic lacks power for action. Therefore, mutations yield in the coronavirus that contrast common beliefs, since a given countries' block $i$ growth path sequences $\left\{G_{n}{ }^{i}\right\}_{n \geq 0, i \epsilon I}$ at each time, $n$, is GDP measurable. Also, its sequences rate at each time $n,\left\{g_{n}{ }^{i}=G_{n+1}{ }^{i} / G_{n}{ }^{i}\right\}_{n \geq 0, i \epsilon I}$, is the associated economic growth rate which converge at least to one finite limit, $g^{i *}$, i.e., the equilibrium in growth rate. Stochastic growth highlighted by the Markovian structure stability is, thus, guaranteed by the closeness property of the subset of $\mathrm{R}$ in which they belong. Thus, the compact property of the set, $\mathrm{C} \supset\left\{C_{i}\right\}_{i \epsilon I} \supset\left\{G_{i}{ }^{n}\right\}_{i \epsilon I, n \in N}$, where $C \subset I \subset R$ thus yields convergence as the necessary condition for growth emergence, i.e., the market-based economy integration and technological change high speed evolution. This results to sufficient condition for catching-up. 


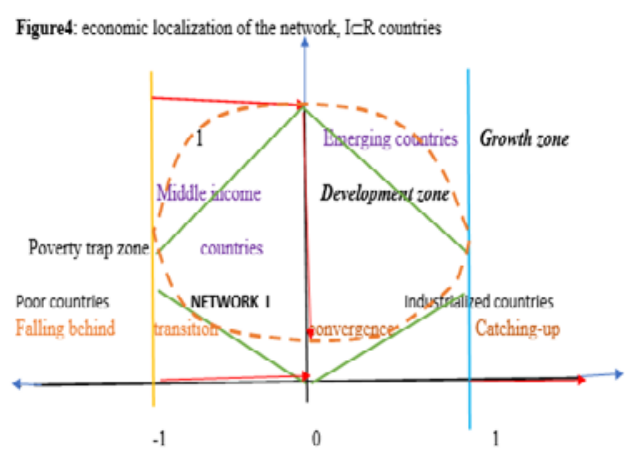

Captions: Yellow Line: Low growth

frontier limit $\left\{g_{n}{ }^{i}\right\}_{n \geq 0, i \in R}<0$, green line frontier limit: Take-off locus: $\left\{g_{n}{ }^{i}\right\}_{n \geq 0, i \epsilon R} \rightarrow 0$, blue line frontier limit, Growth locus, $\left\{g_{n}{ }^{i} \rightarrow g^{i *}\right\}_{n \geq 0, i \in R}$. Where, $g^{i *}=\lim \left\{G_{n}{ }^{i} / G_{n-1}{ }^{i}=g_{n}^{i}\right\}$ is optimal growth path rate. Axis $x$ represent economic development zones and the axis $y$ represents the associated frontier

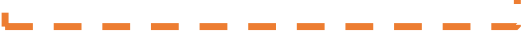

\section{The Methodology Used}

Our study uses modern growth theory in the multi-countries context, as well as mathematical tools, such that the Markovian sequences, $\left\{G_{n}{ }^{i}\right\}_{i \epsilon I, n \in N}$, is moving according to time, $n$, and space, $i \in I \subset R$. Here, the transition probabilities to move from one place to the other is the transition probabilities matrix, $\left\{p_{j k}{ }^{n}\right\}_{i, k \epsilon I}$, which is added to other mathematical tools such as topology, the fixed point, and the separation theorems for the current sanitary crisis of the corona virus modeling purpose. Thus, this extends the standard growth theory literature specifically when the growth path is stochastic and moves according to a given speed with power that depends on technological change growth level. However, in contrast to the usual growth models, the stochastic character of the growth path no more guaranties the equilibrium existence and stability like it does (Denison, 1962). Therefore, in order to establish the longrun growth existence and stability, we assume that countries belong to the subset of the space $\mathrm{R}$ which is a compact, i.e., closed and bounded. Also, each countries' block admits a limit, and it converge at the equilibrium.

However, private agents' equilibrium allocations found using pure mathematics in one part and concavity in linear programming problem, adopted by the social planner by looking at the Pareto optimal equilibrium in the other part, allows stochastic growth path to converge toward a stable equilibrium. The generalization of the separating hyperplan theorem is used to highlights networks break that occur during the confinement period when countries cease connections among them, and when countries were completely isolated along the pandemic eradication first step process. The countries isolation yields multiple closed and bounded sets containing countries. Then, the compactness property of those several sets, thus, guarantees the equilibrium in the countries separately. Also, their numerical experiments needed classification in three kinds: show growth decrease everywhere around the world, that the growth path dynamics, $\left\{G_{n+1}{ }^{i}\right\}_{i \in C, n \geq 0}$, of a given countries' sequences block; $C=\left\{C_{i}\right\}_{i \epsilon I}$, can be stable despite its stochastic character of the dynamics; and $\left\{G_{n+1}{ }^{i}\right\}_{i \epsilon C, n \geq 0}$ consider both over time and space where time is $n+1$ and $i \epsilon C \subset R$ is the space that don't necessarily guaranty the equilibrium 
existence without additional property of the set. Thus, this is because the path moves randomly in contrast to the standard growth theory. Here, the existence and stability of the long-run growth are guaranteed by the equality between population and labor force (Solow, 1956; Denison, 1962). Endogenous growth theory, which originates from the critics of the Solow (1956) model, due to convergence of the whole countries toward the same economic level in the long-run failed to find empirical support to explain what causes the sources of the observed inequalities in the world. After then, it enters endogenous growth theory where marginal capital productivity is constant. Therefore, endogenous growth theory proved increasing returns mechanisms causing growth to be as a result of knowledge accumulation (Romer, 1986), human capital investment (Lucas, 1988; Azariadis-Drazen, 1992), the experience while working (Arrow, 1962), and R\&D (Anant-Dinopoulos, 1990; AghionHowitt, 1992). Then, the least advanced economies, when in exchange with the more advanced economies through networks, generate knowledge spillovers, thus improving growth that can yield convergence and catching-up over time. Therefore, a sudden shock and its transmission becomes a possible event inside a multi-countries exchange partners. Thus, this leads to evictions on the economic projects expected results, and it legitimates the social planner intervention in regard to the violation of the well-being theorem, i.e., the markets' failures.

Consequently, in the case of the current sanitary crisis of "the corona virus", the optimal solution provided by the social planner makes the growth path dynamics, $g_{t+1}{ }^{i}$, to be an increasing function of knowledge. In contrast, the pandemic dynamics, $s_{t+1}{ }^{i}$, is a decreasing function of the economic increasing returns mechanisms, and these curves meet at least once on the space and time. If both curves are monotone, then their interaction is a unique stable equilibrium which is able to eradicate the pandemic (see Figure 5 for local equilibrium existence and stability where the $x$ axis represents the economic policy and the $y$ axis represents the dynamics of growth, $g_{t+1} i$, and of the pandemic, $s_{t+1}{ }^{i}$ ).

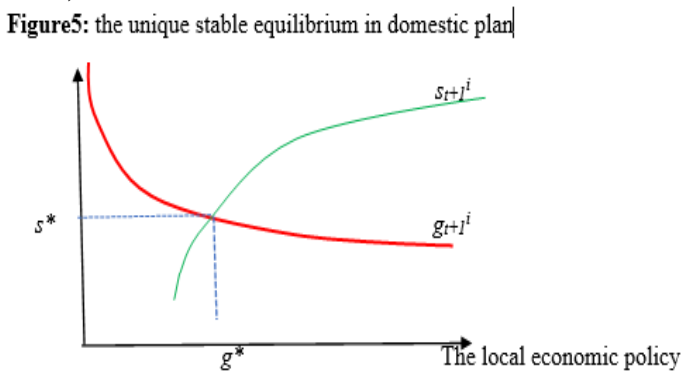

However, local stability of the equilibrium, i.e., inside a given country, deals with the growth path rate dynamics sequences, $\left(g_{t+1}\right)_{t \geq 0, i \epsilon C}$. It is an 
increasing function of technological change in macro level and of income in micro level, which is expected to be an increasing function of the long-run growth mechanisms. In contrast to the pandemic dynamics sequences, $\left(s_{t+1}{ }^{i}\right)_{t \geq 0 \text {,iєC }}$ needs health spending, i.e., medical treatment and prevention while decreasing growth and income. Also, it allows multiple equilibria to be expressed by a sequence couple $\left(s_{n}^{i} ; g_{n}^{i}\right)_{i \epsilon I C n \geq 0}$ even in the same countries' block at the beginning of the emergence of the pandemic. Indeed, each countries' block converge toward a unique equilibrium, $\left(s^{i *} ; g^{i *}\right)_{i \epsilon C}$, along with time. This is as a result of the social planner intervention since each countries' block belongs to a compact set, $C$, which explains the existence of a sequence $\left(s_{n}^{i} ; g_{n}{ }^{i}\right)_{i \epsilon C, n \geq 0}$ such that $\left(s_{n}^{i} ; g_{n}{ }^{i}\right)_{i \epsilon C, n \geq 0} \rightarrow\left(s^{i *} ; g^{i *}\right)_{i \in C}$ due to the compactness of the countries' sequences set, $C \supset\left\{C_{i}\right\}_{i \in C}$, of the network. Subsequently, local equilibrium is stable in each given country of a given countries' block as displayed in Figure 5 below. Stable equilibrium is Pareto optimal. Consequently, the deal is to allow the global equilibrium existence and stability that is shown later on or in the theory application context using data observations.

Lemma 1, Network Space Delimitation: If a given countries' block $C=\left\{C_{i}\right\}_{i \in C}$, i.e., the association of several similar countries that belongs to the network I, then those countries are integrated economies, i.e., are in transition toward the global market. Otherwise, they are marginalized since they are far away from the new world economic thought.

Proof: Let two different countries sequences blocks $C=\left\{C_{i}\right\}_{i \in C}$ and $D=\left\{D_{j}\right\}_{j \in D}$ be such that, $\left.\left\{C_{i}\right\}_{i \epsilon C} \subset\right]-\infty,-1\left[=C\right.$ and $\left.\left\{D_{j}\right\}_{j \in D} \subset\right] 1,+\infty[=D$ in the R axis. Here, there exists the closed ball of center 0 and of radius 1 . Therefore, $B(0,1) \approx[-1,+1]$ is a compact set and, thus, the countries located inside ensures both the existence and the stability of the equilibrium. Indeed, since, on the one hand, $\left\{C_{i}\right\}_{i \epsilon C}<-1$ and $\left\{D_{j}\right\}_{j \in D}>1$, there exist $\operatorname{Sup}\left\{x_{n}{ }^{i}\right\}_{n \geq 0, i \in C}=M=1>-\infty$. This is such that the sub-sequences $\left\{x_{n}{ }^{i}\right\}_{n \geq 0} \subset\left\{C_{i}\right\}_{j \in C}$ yields $\left\{x_{n}{ }^{i}\right\}_{n \geq 0, i \in C}$ and converge to $\{1\}$, which is not included in $\left\{C_{i}\right\}_{i \in C}$ and there also exist $\operatorname{Inf}\left\{x_{n}{ }^{i}\right\}_{n \geq 0}=x^{*}$. Therefore, the Min and the Sup are not reached by $C$. On the other hand, since $\operatorname{Inf}\left\{\left(y_{n}^{j}\right)\right\}_{n \geq 0, j \in D}=m=+1$ exist for the sub-sequences, $\left\{y_{n}{ }^{j}\right\}_{n \geq 0} \subset\left\{D_{j}\right\}_{j \in D}$, then it converge at $y^{*}$ where, $y^{*}=\operatorname{Sup}\left\{y_{n}^{j}\right\}_{n \geq 0, j \in D^{<}}<+\infty$ since it exist. Therefore, before the beginning of the economic policy, the network $I \subset R$ is approximated by $\left.I \approx\left[x^{*}, 0[U[0,+1]) U\right] 1, y^{*}\right]$. Thus, this is a set of integrated economies' sequences composed of $N$ countries. Also, it is indexed by $i \epsilon\{1,2, \ldots, N\}$, irrespective of where they are geographically located. Consequently, outside the set $I$, all the countries located inside $\left[-\infty, x^{*}\right]$ are considered to be marginalized economies.

The article presentation is done through the following. Section II provides the theory, section III shows sudden shocks in connected countries and transmission risks, section $I V$ highlights risk impact on the international 
economy, section $V$ highlights the social planner's intervention, section $V I$ focuses on the numerical experiments of the theory, section VII provides the macroeconomics' empirical view of the theory elaborated, and section VIII concludes on this study.

\section{The Theory}

\section{The Private Agents}

Lemma 2: Since two different countries sequences blocks, $C=\left\{C_{i}\right\}_{i \epsilon I}$ and $D=\left\{D_{j}\right\}_{j \epsilon l}$, partnerships in the network $I$, then, according to assumption 1 , the sum of those countries' $C+D$ is also a compact set. Thus, it is closed and bounded.

Proof: Since the countries' sequences, $C=\left\{C_{i}\right\}_{i \epsilon I}$ and $D=\left\{D_{j}\right\}_{j \epsilon I}$, belong to the network, $I \subset R$, where $R$ is a metric space, then $I$ as well as $C$ and $D$ are also metric spaces such that those countries relationships between $C$ and $D$ in $I$ are summarized by a matrix, $A=\left(a_{i j}\right)_{i, j}$ of format $(N, N)$. Thus, it is diagonalizable since it is a squared matrix format. It admits an eigenvalues sequences, $\left\{\lambda_{i}\right\}_{n \geq 0, i \epsilon}$, which if the product is negative and the sum is positive, then the countries' sequences block, $C=\left\{C_{i}\right\}_{i \epsilon I}$ and $D=\left\{D_{j}\right\}_{j \epsilon I}$, admit a stable solution, i.e., each growth path equilibrium sequences, $\left\{g_{n}{ }^{i}\right\}_{n \geq 0, i \in C}$. and $\left\{g_{n}^{j}\right\}_{n \geq 0, j \in D}$. Here, the sum converges toward a unique equilibrium, $g^{*}$, such that $\left(g^{i *}+g^{j *}\right) / 2 \rightarrow g^{*}$ when $n \rightarrow \infty$. Moreover, since the matrix $A$ is also invertible, the corresponding partners relationships is a bijective function (solutions are fixed points). Thus, the connections are strong. Indeed, the countries sequences partnerships blocks, $C=\left\{C_{i}\right\}_{i \epsilon I}$ and $D=\left\{D_{j}\right\}_{j \epsilon l}$, are endowed respectively by the Markov growth paths sequences, $\left\{G_{n}{ }^{i}\right\}_{n \geq 0, i \epsilon C}$ and $\left\{G_{n}{ }^{j}\right\}_{n \geq 0, j \in D}$, such that $\mathrm{P}\left(G_{n}{ }^{i}+G_{n}{ }^{j}=\mathrm{n}+\mathrm{m} / G_{0}{ }^{i}+G_{0}{ }^{j}=k+l, G_{1}{ }^{i}+G_{1}{ }^{j}=(k+l)+1\right.$, \}$_{n \geq 0, i \in C, j \in D}$. Thereafter, the growth paths sum, $\left\{G_{n}{ }^{i}+G_{n}{ }^{j}\right\}_{n \geq 0, j \epsilon I}$, yield a positive existence, $\varepsilon^{0}$, such that $\left\{d\left(G_{n}{ }^{i}, G_{n}^{j}\right)\right\}_{n \geq 0, i, j \in I}<\varepsilon^{0}$. This means that there exist $\left\{\varepsilon^{0}\right\}>0$ such that the sequences, $\left\{G_{n}{ }^{i}+G_{n}{ }^{j}\right\}_{n \geq 0, i \epsilon C, j \in D} \rightarrow\left\{G_{0}{ }^{i}+G_{0}{ }^{j}\right\}_{i \epsilon C, j \in D}$, converge toward a finite limit over time. Thus, when $n \rightarrow \infty$ and in distance terms, it yields $\left\{d\left(G_{n}{ }^{i}+G_{n}{ }^{j}\right),\left(G_{0}{ }^{i}+G_{0}{ }^{j}\right)\right\}_{n \geq 0, i \epsilon C, j \epsilon D} \leq \varepsilon^{0} / 2$ for all $n \geq 0$. Indeed, $\operatorname{Sup}\left\{d\left(\left(G_{n}{ }^{i}+G_{n}{ }^{j}\right),\left(G_{0}{ }^{i}+G_{0}{ }^{j}\right)\right\}_{n \geq 0, i \epsilon C, j \in D}=\left\{G_{0}{ }^{i *}+G_{0}{ }^{j} *\right\}_{i \epsilon C, j \in D}\right.$ exist. Therefore, that sequences sum is of Cauchy, i.e., $\left\{d\left(G_{n}{ }^{i},+G_{n}{ }^{j}, G_{m}{ }^{i},+G_{m}{ }^{j}\right)\right\}_{n, m \geq 0, i \in C, j \in D} \leq\left\{\varepsilon^{0} / 2\right\}_{i \epsilon I}$. Indeed, the sum of the sets, $C+D$, is compact since $C=\left\{C_{i}\right\}_{i \epsilon I}$ and $D=\left\{C_{j}\right\}_{j \epsilon I}$ are individually compact sets of $I \subset R$, i.e., closed and bounded sets. Thus, the sum of the whole existing sequences in $I$ admits a stable equilibrium.

Lemma 3: According to Lemma 2, if $M$ different countries sequences blocks $C=\left\{C_{1}, C_{2}, C_{3}, \ldots, C_{M}\right\}_{i \epsilon l}$ are partnerships in the network, $I=\sum_{i=1}{ }^{M} C_{i}$, then, the sum of the whole of them, $C=C_{1}+C_{2}+C_{3}+\ldots+C_{M}$, is a closed and bounded exchange zone.

Proof: if $M=2$, then by Lemma 2, $C=C_{1}+C_{2}$ is a closed and bounded exchange zone. Indeed, assuming $C=C_{1}+C_{2}+C_{3}+\ldots+C_{M}$ to be a closed and 
bounded exchange zone, then if $D=C_{M+1}$ is a compact set partner of $C$, by Lemma 2, the sum $C+D$ is also a closed and bounded zone. Also, $C+D=C_{1}+C_{2}+C_{3}+\ldots+C_{M+1}$ is a closed and bounded exchange zone too

Definition 1: Each country's sequences block, $C=\left\{C_{i}\right\}_{i \epsilon}$, of the network $I$ is characterized by a Markov growth path sequences, $\left\{G_{n}{ }^{i}\right\}_{n \geq 0}$, and $N$ knowledge exchange partners sequences $\left(H_{1}, H_{2}, \ldots, H_{N}\right)$. It is summarized by a function $f$, defined on $C$, and takes its values on $\left\{H_{i}\right\}_{i \epsilon I}$.

Definition 2 (Generalization): Let several countries blocks, $C=C_{1}+C_{2}+C_{3}+\ldots+C_{M}$, of the network $I$ be partnership in exchange. Thus their relationships is summarized by a $(N, N)$ matrix. $A=\left(H_{i, j}\right)_{i, j \in I}$ is a diagonalizable matrix since it has the same number of line and columns, thus ensuring stability in the exchanges when the eigenvalues of the matrix verify a positive sum and a negative product.

Definition 3: Since each Markov growth path sequences, $\left\{G_{n}{ }^{i}\right\}_{n \geq 0, i \epsilon}$, of the countries' sequences block, $C=\left\{C_{i}\right\}_{i \epsilon \epsilon}$, is characterized by the transition probability matrix, then the blocks vector $\left(C_{1}, C_{2}, C_{3}, \ldots, C_{M}\right)$ admits a transition probabilities matrix $P=\left(P\left(\left\{G_{n}{ }^{i}\right\}_{n \geq 0, i, j \epsilon I}\right)\right)=\left(p_{j k}{ }^{n}\right)_{n \geq 0, i, j, k \epsilon I}$ such that $\left.\left\{\left(p_{j k}{ }^{n}\right)^{i}\right\}_{j, k \in C, n \geq 0}=P\left(G_{n}{ }^{i}=k_{0}, G_{n}{ }^{j}=k_{1}, \ldots, G_{n}{ }^{m}=k_{m+n} j / G_{0}{ }^{i j}=i\right)\right\}_{n \geq 0, i, j \epsilon \epsilon}$. $\left.=\bigcap_{n \geq 0, l, j, l \epsilon I} P\left(G_{n}{ }^{i}=k i / G_{m}{ }^{i}=k j\right) P\left(G_{n-1}{ }^{i}=k i / G_{m-1}{ }^{j}=h, \ldots, G_{0}{ }^{l}=k_{0}\right)\right\}$ $=\prod n \geq 0, l, j, l \epsilon\left\{\left\{\left(p_{k j}\right)^{i}\right\}\left\{\left(p_{i k}{ }^{n}\right)^{i}\right\}_{n \geq 0, i \in C}\right.$ and $\sum_{n \geq 0}\left(\sum_{i, j \epsilon C}\left(p_{j k}\right)^{i}\right)=1$ when independency among countries' blocks is verified

Lemma 4: The equilibrium of the economy, $C_{i}$ of a given countries' sequences block, $C=\left\{C_{i}\right\}_{i \in I}$, is characterized by the sequences vector, $\left(\left\{G_{n}{ }^{i}\right\}_{n \geq 0}\right.$ $\left.,\left\{p_{j k}{ }^{i}\right\}_{j, k \in S},\left\{g_{n}{ }^{i}\right\}_{n \geq 0},\left\{v_{n}{ }^{i}\right\}_{n \geq 0},\left\{A_{n}{ }^{i}\right\}_{n \geq 0}\right)$.

Proof: Given the Markov growth path vector $\left\{G_{n}{ }^{i}\right\}_{n \geq 0}$ of country $C_{i}$ $\subset C=\left\{C_{i}\right\}_{i \epsilon I}$ by Definition 1, its transition probabilities vector, $\left\{p_{j k}{ }^{i}\left(G_{n}{ }^{i}\right)_{n \geq 0}\right\}_{j, k \epsilon S}$, and its growth rate vector, $\left\{g_{n}{ }^{i}=\left\{g_{n}{ }^{i}\left(h_{n}{ }^{i}\right)\right\}_{n \geq 0}\right.$, exist and increase with knowledge accumulation. Then its Markov growth path moves from one stage to the other, according to a velocity vector $\left\{v_{n}^{i}\right\}_{n \geq 0}=\left\{v_{n}^{i}\left(G_{n+1}{ }^{i}\right)\right\}_{n \geq 0}$ which power depends on technological change level, $h_{j i}{ }^{n}$. Thus, at time $n$, the country $i$ is in exchange trade with country $j$, a by-product of knowledge acquired in the education sector or the experience when working. The whole of this is summarized by $\left\{A_{n}{ }^{i}\left(C_{i}\right)\right\}_{n \geq 0}$, i.e., the relationship with his partners in exchange trade.

Lemma 5: The Markov growth path of the country, $C_{i} \subset C=\left\{C_{i}\right\}_{i \epsilon I}$, i.e., $G_{n+1}{ }^{i}=f\left(G_{n}{ }^{i}\right)$, moves according to the speed, $v_{i}{ }^{n}\left\{\left(h_{j i}{ }^{n}\right)\right\}$, and converge toward the maximum, $v^{i}\left(\left(h_{i j}{ }^{n}\right)_{n \geq 0, i, j \in C}\right)=p\left(G^{i *}\right)=\left[\partial\left\{\left(p_{k j}\right)^{i}\right\} / \partial t\right]\left[\partial\left\{\left(p_{i k}{ }^{n}\right)^{i}\right\} / \partial t\right]_{n \geq 0, i \epsilon I}$ when technological change level accelerates and yields $v_{i}^{n}\left\{\left(p_{j k}\right)^{i}\right\}_{n \geq 0, i, k \in C} \rightarrow v^{i}\left(\left(h_{i j}{ }^{n}\right)_{n \geq 0, i \in C}\right)$ where, $\Sigma_{n \geq 0}\left(\sum_{i, j \in C}\left(p_{j i}{ }^{n}\right)\right)=1$.

Proof: According to mathematical theory, a given process, $\left\{G_{n}{ }^{i}\right\}_{n \geq 0}$, results from the dynamics, $\left.\left\{G_{n+1}{ }^{i}\right\}=f\left(G_{n}{ }^{i}\right)\right\}_{n \geq 0, i \in C}$, and through Lemma 4 , the dynamics sequences moves according to a velocity sequences, 
$\left.\left\{v_{n}{ }^{i}\right\}\left(h_{i j}{ }^{n}\right)\right\}_{n \geq 0, i, j \in C}=\left\{\partial G_{n}{ }^{i} / \partial G_{n-1}{ }^{i}\right\}_{n \geq 0, i \epsilon C}$. Thus, this is the speed of convergence of the growth path dynamics over time, $n \geq 0$. Therefore, in the long-run, since the sequences $\left.\left\{v_{n}{ }^{i}\right\}\left(h_{i j}{ }^{n}\right)\right\}_{n \geq 0, i, j \in C}=\left\{\partial G_{n+1}{ }^{i} / \partial G_{n}{ }^{i}\right\}_{n \geq 0, i \in C}$ is included inside a compact set, it converges at the limit, $v^{i}\left(h^{i *}\right)$. Therefore, $\left.\left\{G_{n+1}{ }^{i}\right)\right\}_{n \geq 0, j, k \epsilon I}$ converge at $G^{i^{*}}$. Finally, in the long-run, the growth path dynamics moves according to $v^{i}=p\left(h^{i *}\right)$.

Lemma 6: Let the growth path sequences dynamics of the countries' sequences block, $C=\left\{C_{i}\right\}_{i \epsilon}$, i.e., $\left\{G_{n+1}{ }^{i}\right\}_{n \geq 0, i \epsilon}$, moves according to the velocity sequences, $\left.\left\{v_{n}{ }^{i}\right\}\left(h_{i j}{ }^{n}\right)\right\}_{n \geq 0, i, j \in C}=\left\{F\left(h_{i j}{ }^{n}\right)\right\}_{n \geq 0, I, j \in C}=\left\{\partial G_{n+1}{ }^{i} / \partial G_{n}{ }^{i}\right\}_{n \geq 0, i \epsilon I}$. Then, in the long-run, the resulting growth path rate sequences, $\left\{g_{n}{ }^{i}=G_{n+1}{ }^{i} / G_{n}{ }^{i}\right\}_{n \geq 0, i \epsilon I}$, converge or catch-up the leader's economic performance faster, if $\left\{v_{n}{ }^{i}\right\}_{n \geq 0, i \epsilon I} \rightarrow v^{i *}=\operatorname{Sup}\left\{v_{n}{ }^{i}\left(h_{i j}{ }^{n}\right)\right\}_{n \geq 0, i, j \in C}$ over time.

Proof: Using Lemma 4, the growth path dynamics sequences, $\left\{G_{n+1}{ }^{i}=f\left(G_{n}{ }^{i}\right)\right\}_{n \geq 0} \subset C=\left\{C_{i}\right\}_{i \epsilon I}$, moves according to the velocity $\left\{v_{n}{ }^{i}\left(h_{i j}{ }^{n}\right)\right\}_{n \geq 0, i, j \in C}$ (according to Lemma 2). Then, as time $n$ goes toward $\infty$, the velocity sequences also converge, i.e., $\left.\left\{v_{n}{ }^{i}\right\}\left(h_{i j}{ }^{n}\right)\right\}_{n \geq 0, i j \in C} \rightarrow\left\{v^{i *}\right\}_{i \epsilon I}$. Thus, the growth path sequences, $\left\{G_{n+1}{ }^{i}=f\left(G_{n}{ }^{i}\right)\right\}_{n \geq 0, i \epsilon I}$, also converge at its limit very fast at a fewer time, $m^{*}$, such that $m^{*}=\operatorname{Inf}\left\{m\right.$ and $\left\{v_{n}^{i}\left(h_{i j}{ }^{n}\right)\right\}_{n \geq 0, i, j \in C} \rightarrow\left\{v^{i *}\right\}_{i \in C}$ $\left.\geq\left\{G_{n+1}{ }^{i}=f\left(G_{n}{ }^{i}\right)\right\}_{n \geq 0} \quad \rightarrow\left\{G^{i *}\right\}_{i \epsilon \epsilon}\right\} \quad$ where $\quad\left\{v^{i *}\right\}_{i \epsilon C} \quad=\operatorname{Max}\left\{\partial G_{n}{ }^{i} \quad / \partial G_{n-1}{ }^{i}\right\}_{n \geq 0}$ $i \in\{1,2, \ldots, N\}$. Therefore, catching-up occurs.

\section{The Theoretical Results}

Proposition 1: Let the economy of a given countries sequences block, $C=\left\{C_{i}\right\}_{i \epsilon l}$, be characterized by the sequences vector $\left(\left\{G_{n}{ }^{i}\right\}_{n \geq 0},\left\{p_{j k}{ }^{i}\right\}_{j, k \epsilon S},\left\{g_{n}{ }^{i}\right\}_{n \geq 0}\right.$, $\left.\left\{v_{n}{ }^{i}\right\}_{n \geq 0},\left\{A_{n}{ }^{i}\right\}_{n \geq 0}\right)_{n \geq 0, i \epsilon I}$. Thus, the necessary condition for economic transition toward market-based economy is convergence in knowledge terms, i.e., $\left\{h_{n+1}{ }^{i, j}=h_{n}{ }^{i}+h_{n}{ }^{j(i)}\right\}_{n \geq 0, i, j \epsilon I} \rightarrow\left\{h^{i, j *}\right\}_{i \epsilon I}=\operatorname{Sup}\left\{h_{n}{ }^{i, j}\right\}_{n \geq 0, i, j \in I}$ over time.

Proof: According to the literature, domestic knowledge is provided by incentives to invest in human capital accumulation, $\left\{h_{n+1}\right\}_{n \geq 0, i \epsilon C}$. This is a sum of knowledge spillovers provided by exchanges with other partners $\left\{h_{n}{ }^{j(i)}\right\}_{n \geq 0, i, j \epsilon I}$ and the average domestic knowledge, $\left\{h_{n}{ }^{i}\right\}_{n \geq 0, i, j \epsilon I}$. Indeed, knowledge accumulation, $\left\{h_{n+1}{ }^{i, j}=h_{n}{ }^{i}+h_{n}{ }^{j(i)}\right\}_{n \geq 0, i, j \epsilon I}$, is able to yield convergence and catching-up faster if is high enough depending on the growth path speed. If high, then, $\left\{h_{n+1}{ }^{i, j}\right\}_{n \geq 0} \rightarrow\left\{h^{i *}\right\}_{i \epsilon I}=\operatorname{Sup}\left\{h_{n}{ }^{i, j}\right\}_{n \geq 0, i, j \epsilon I}$. Thus, it is the necessary condition of convergence and catching-up toward more advanced economies "knowledge".

Proposition 2: The sufficient condition, respectively, for convergence and catching-up to occur is the existence of a high technological change speed parameter, $\left\{\varepsilon_{v\left(G i^{*}\right)}\right\}_{i \epsilon I}>0$. If $\left\{\varepsilon_{v\left(G i^{*}\right)}\right\}_{i \in C} \rightarrow \operatorname{Max}\left\{v\left(\partial h_{n+1}{ }^{i} / \partial h_{n}{ }^{i}\right)\right\}_{n \geq 0, i \in C}$, then catching-up occurs, otherwise if $\left\{\varepsilon_{v\left(G i^{*}\right)}\right\}_{i \epsilon C} \rightarrow \operatorname{Sup}\left\{v\left(\partial h_{n+1}{ }^{i} / \partial h_{n}{ }^{i}\right)\right\}_{n \geq 0, i \epsilon I}$ then convergence occurs. 
Proof: Using Proposition 1, human capital, R\&D, and technology, i.e., knowledge of the country, $C i$ is the sequences $\left\{h_{n}{ }^{i}\right\}_{n \geq 0, i \in C}$ such that it accumulates according to $\left\{h_{n+1}{ }^{i}=K\left(h_{n}{ }^{i}\right)\right\}_{n \geq 0, i \in C}$. Since technological change $\left\{\varepsilon_{v(G i)}\right\}_{i \epsilon I}=\left\{v\left(\partial h_{n+1}{ }^{i} / \partial h_{n}{ }^{i}\right)\right\}_{n \geq 0, i \epsilon \epsilon}$, where $\left\{g_{n}^{i}=h_{n+1}{ }^{i} / h_{n}{ }^{i}\right\}_{n \geq 0}$ is the growth rate sequences, knowledge increase yields. Also, the least advanced countries' sequences block, $C=\left\{C_{i}\right\}_{i \epsilon I}$, transits toward more advanced countries block, $D=\left\{D_{k}\right\}_{k \in D}$. After then, $C$ converged at $D$ over time. Otherwise, if technological change sequences of $C_{i},\left\{\varepsilon_{v(G i)}\right\}_{i \epsilon l}=\left\{\left\{v\left(\partial h_{n+1}{ }^{i} / \partial h_{n}{ }^{i}\right)\right\}_{n \geq 0, i \in C}\right.$, converge toward the highest level, $\operatorname{Max}\left\{v\left(\partial h_{n+1}{ }^{i} / \partial h_{n}{ }^{i}\right)\right\}_{n \geq 0, i, j \in I}=\left\{\varepsilon_{v\left(G i^{*}\right)}\right\}_{i \epsilon I}$ $>\left\{\varepsilon_{v\left(G k^{*}\right)}\right\}_{k \epsilon \epsilon}$, then the follower countries sequences block, $C=\left\{C_{i}\right\}_{i \epsilon C}$, catch-up the leading countries' sequences, $D=\left\{D_{k}\right\}_{k \in D}$. This is because the follower countries growth path sequences is inside a closed ball, i.e., $\left\{G_{n+1}{ }^{i} \subset B\left(G_{n+1}{ }^{k}\right.\right.$, $\left.\varepsilon_{v\left(G i^{*}\right)}\right\}_{n \geq 0, i \epsilon C} \subset\left\{\varepsilon_{v(G k)}\right\}_{k \in D}$. This is in addition to the ball of center, $\left\{G_{n+1}{ }^{k}\right.$ \}$_{n \geq 0, k \in D}$, and of radius, $\left\{\varepsilon_{v\left(G k^{*}\right)}\right\}_{k \in D}$. Thus, $C$ converge to a finite limit, and it becomes locally stable.

Proposition 3: Let the countries sequences block, $C=\left\{C_{i}\right\}_{i \epsilon I} \subset I$, be a compact set endowed with a Markov growth path dynamics sequences, $\left\{G_{n+1}{ }^{i}\right\}_{n \geq 0, i \epsilon C}$, moving at the velocity, $v^{i *}=\operatorname{Max}\left\{\left\{v_{n}{ }^{i}\right\}\left(h_{i j}{ }^{n}\right)\right\}_{n \geq 0, i j \in C}$. Then, the equilibrium sequences, $\left\{\left(g^{i *}, h^{i *}\right)\right\}_{i \epsilon I}$, that ensures convergence and catchingup over time exist and is stable.

Proof: Since the growth path dynamics sequences, $\left\{G_{n+1}{ }^{i}\right\}_{n \geq 0, i \epsilon C \subset} \subset C=\left\{C_{i}\right\}_{i \epsilon I} \subset I$, is a compact countries' sequences set endowed with the velocity dynamics sequences, $\left\{\left\{v_{n}{ }^{i}\right\}\left(h_{i j}{ }^{n}\right)\right\}_{n \geq 0, i, j \in C}$, with such moving at its limit $\operatorname{Max}\left\{v\left(G_{n}{ }^{i}\right)\right\}_{n \geq 0, i \epsilon I}$, then the knowledge accumulation sequences, $\left\{h_{n+1}{ }^{i}\right\}_{n \geq 0, i \epsilon I}$, will converge to its maximum, i.e., $\operatorname{Max}\left\{h_{n}{ }^{i}\right\}_{n \geq 0, i \epsilon \text {. }}$. This is due to technological change in high speed, i.e., $\operatorname{Max}\left\{v\left(\partial h_{n+1}{ }^{i} \partial h_{n}{ }^{i}\right)\right\}_{n \geq 0, i, j \in I}=\left\{\varepsilon_{v(G i *}\right\}_{i \epsilon I}$ is reached. Thus, this made the growth path sequences, $\left\{g_{n}^{i}\left(h_{n}^{i}\right)\right\}_{n \geq 0, i \epsilon}$, to converge at the maximum sequences limit, $\operatorname{Max}\left\{g^{i}\left(h_{n}^{i}\right)\right\}_{n \geq 0, i \in C}$. Consequently, since $\operatorname{Max}\left\{g_{n}^{i}\left(h_{n}{ }^{i}\right)\right\}_{n \geq 0, i \epsilon C} \rightarrow\left\{g\left(h^{i *}\right)=g^{i *}\right\}_{i \epsilon C}$ and $\operatorname{Max}\left\{\left(h_{n}{ }^{i}\right)\right\}_{n \geq 0, i \epsilon C} \rightarrow\left\{h^{i *}\right\}_{i \epsilon C}$, then the equilibrium sequences, $\left(g^{i *}, h^{i *}\right)_{i \in D}$, that ensures that convergence and catching-up exist is stable. Since they are included in the compact set $\left\{C_{i}\right\}_{i \epsilon I}$, it is located at the boundary of the set.

Example 1: Let the countries' sequences $C=\left\{C_{i}\right\}_{i \epsilon I}$ be endowed with a Markov dynamics sequences, $\left\{G_{n+1}{ }^{i}\right\}_{n \geq 0, i \epsilon C}=\left\{x_{n+1}{ }^{i}\right\}_{n \geq 0, i \epsilon C}$ and follow a gaussian distribution, $N\left(E\left(x_{n}{ }^{i}\right), \operatorname{Var}\left(x_{n}{ }^{i}\right)\right)$. There exist a sequences $\left\{X_{n}{ }^{i}\right\}_{n \geq 0, i \in C}$, such that $\left.\left\{X_{n}{ }^{i}=\left(x_{n}{ }^{i}-E\left(x_{n}{ }^{i}\right)\right) / \operatorname{Var}\left(x_{n}{ }^{i}\right)\right)\right\}_{n \geq 0, i \epsilon C}$, which follows a centered and reduced Gaussian distribution, $N(0,1)$ where $\left\{E\left(x_{n}^{i}\right)\right)=0$ and $\left.\operatorname{Var}\left(x_{n}^{i}\right)=1\right\}_{n \geq 0, i \epsilon C}$, and then the associated density probability sequences, $\left\{f_{n}^{i}(x)\right\}_{n \geq 0, i \epsilon I}=\left\{(1 / 2 \pi)^{-1 / 2} \exp \{\right.$ $\left.\left.x^{2} / 2\right\}\right\}, n \geq 0$. Indeed, the expectation for the chain $\left\{G_{n+1}\right\}_{n \geq 0, i \in C}$ to be at the stage $k$ if it begins at the stage 0 is, $\{E(X=x)\}=\left\{\int_{x}=0^{k} x(1 / 2 \pi)^{-1 / 2} \exp \left\{-x^{2} / 2\right\} d x\right\}=\left\{(1 / 2 \pi)^{-}\right.$ $\left.{ }^{1 / 2}\left[-\exp \left\{-x^{2} / 2\right\}\right]_{0}^{k}\right\}$ since the sequences $\left\{x_{n}^{i}\right\}_{n \geq 0, i \epsilon I}$ converge to $x^{*}$ when $n$ tends to $\infty$. 
Since $\left\{x_{n}{ }^{i}\right\}_{n \geq 0, i \epsilon C}$ converge, then $\left\{x_{n+1}{ }^{i} / x_{n}{ }^{i}\right\}_{n \geq 0, i \epsilon C}=\left\{g_{n}{ }^{i}\left(h_{n}^{i}\right)\right\}_{n \geq 0, i \epsilon C} \rightarrow g^{i *}$ and $\left\{h^{i}\right\}_{i \epsilon C} \rightarrow h^{* i}$ for all fixed $i \epsilon C$. Thus, $x^{i *}=\left(g^{i *}, h^{i *}\right)$ ensures that convergence and catching-up possibility over time exist and is stable since it is included in a compact set, $C=\left\{C_{i}\right\}_{i \epsilon I}$. Then $\left\{(1 / 2 \pi)^{-1 / 2}\left[1-\exp \left\{-k^{2} / 2\right\}\right]\right\} \rightarrow 0$ when $k \rightarrow+\infty$ where, $\left.\left\{X_{i}\right\}_{i \epsilon C}=\left\{x_{n}{ }^{i}\right\}_{n \geq 0, i \epsilon C} \rightarrow x^{i *}=\left(g^{i *}, h^{i *}\right)\right\}$ is the stable equilibrium.

Example 2: According to Example 1, if the countries' sequences block, $C=\left\{C_{i}\right\}_{i \in C}$, growth path dynamics sequences moves at the maximum speed, then the associated growth path rate sequences, $\left\{g_{n}{ }^{i}=G_{n+1}{ }^{i} / G_{n}{ }^{i}\right\}_{n \geq 0, i \epsilon C}$, converge surely to the optimum growth path rate, $\operatorname{Max}\left\{g_{n}{ }^{i}\right\}_{n \geq 0, i \epsilon C}$ $=\operatorname{Max}\left\{G_{n+1}{ }^{i} / G_{n}^{i}\right\}_{n \geq 0, i \epsilon C} \rightarrow\left\{g^{i *}\right\}_{i \epsilon C}$. Therefore, the countries' sequences, $C=\left\{C_{i}\right\}_{i \epsilon}$, converge toward more advanced economies and may catch up with the industrialized countries' sequences block over time. Consequently, the maximum speed if reached yields catching-up, otherwise if not, the follower countries would block the move at the same constant rate. As the more advanced countries' block, then convergence is likely to occur over time. More precisely, there exist time sequences, $\left\{\tau^{i}\right\}_{i \in C}>0$, defined by $\left\{\tau^{i}\right\}_{i \in C}=\operatorname{Inf}\{n \geq 0$. This is such that if the growth path sequences block, $C$ moves at the same constant rate as the more advanced economies at the average speed, i.e., $\left(g_{n}^{i}\right)_{n \geq 0, i \epsilon C} \rightarrow\left(g^{i *}\right)_{i \epsilon C}$ (convergence). Otherwise, if the growth path sequences block, $C$ moves at the speed, $\left\{\tau^{i}\right\}_{i \epsilon C},\left\{g^{i *}\right\}_{i \epsilon}=\operatorname{Sup}\left\{g_{n}{ }^{i}\right\}_{n \geq 0, i \epsilon C}=\operatorname{Max}\left\{G_{n+1}{ }^{i} / G_{n}{ }^{i}\right.$ \}$_{n \geq 0, i \in C}$ and the growth path rate sequences is reached over time. Thus, this allows for catching-up.

Proposition 4: Given two different countries sequences blocks, $C=\left\{C_{i}\right\}_{i \epsilon I}$ and $D=\left\{D_{j}\right\}_{j \epsilon I}$ in the network $I$, with respective growth rate paths sequences, $\left\{g_{n}{ }^{i}\right\}_{n \geq 0, i \epsilon C}$ and $\left\{g_{n}{ }^{j}\right\}_{n \geq 0, i \epsilon D}$ where $\left\{g_{n}{ }^{i}\right\}_{n \geq 0, i \epsilon C}<\left\{g_{n}{ }^{j}\right\}_{n \geq 0, i \epsilon D}$, then the countries' sequences block, $C=\left\{C_{i}\right\}_{i \epsilon I}$, converge or catch-up with the countries' sequences block, $D=\left\{D_{j}\right\}_{j \epsilon I}$ if and only if, the respective technological change parameters speed is such that, $v(C)=\left\{v\left(\partial h_{n+1} i^{i} / \partial h_{n}{ }^{i}\right)\right\}_{n \geq 0, i \epsilon} \geq v(D)=\left\{v\left(\partial h_{n+1}{ }^{j} / \partial h_{n}{ }^{j}\right)\right\}_{n \geq 0, j \epsilon \epsilon}$.

Proof: Since two different countries sequences are characterized by their respective growth path rate sequences, $\left\{g_{n}{ }^{i}\right\}_{n \geq 0, i \in C}$ and $\left\{g_{n}{ }^{j}\right\}_{n \geq 0, i \in D}$, such that at the boundary $\left\{g^{i *}\right\}_{i \epsilon C}<\left\{g^{j *}\right\}_{j \in D}$ since the both technological change converge, i.e., $\left\{v\left(\partial h_{n+1}{ }^{i} / \partial h_{n}{ }^{i}\right)\right\}_{n \geq 0, i \epsilon C} \rightarrow\left\{v\left(\partial h_{n+1}{ }^{j} / \partial h_{n}{ }^{j}\right)\right\}_{n \geq 0, j \in D}$ when $n \rightarrow \infty$, then the least advanced countries' sequences block $C=\left\{C_{i}\right\}_{i \in I}$ would also converge at the more advanced countries' sequences block, $D=\left\{D_{j}\right\}_{j \in D}$. Therefore, the same result holds for the growth path rate sequences, and thus convergence occurs. Otherwise if $\left\{v\left(\partial h_{n+1}{ }^{i} / \partial h_{n}{ }^{i}\right)\right\}_{n \geq 0, i \epsilon C} \geq\left\{v\left(\partial h_{n+1}{ }^{j} / \partial h_{n}{ }^{j}\right)\right\}_{n \geq 0, j \in D}$, then the countries' sequences block $C=\left\{C_{i}\right\}_{i \epsilon I}$ catch-up the more advanced countries' sequences block, $D=\left\{D_{j}\right\}_{j \in D}$.

Theorem 1: Let the Markov growth path dynamics sequences $\left\{G_{n+1}^{i}\right\}_{n \geq 0, i \epsilon I}$ of the compact and metric countries sequences set, $C=\left\{C_{i}\right\}_{i \epsilon I}$, 
moves according to the velocity, $\left\{v_{n}^{i}\right\}_{n \geq 0, i \in C}=\left\{v\left(\partial h_{n+1}{ }^{i} \partial h_{n}^{i}\right)\right\}_{n \geq 0, i \epsilon C}$. Thus, the general equilibrium of the whole sequences block $\left(g^{i *}, h^{i *}\right)$ exist in the network I, and is stable, since $\left.\left\{g^{i}\left(h_{n}{ }^{i}\right\}\right)\right\}_{n \geq 0, i \epsilon I} \rightarrow g^{i *}\left(h^{i *}\right\}_{i \epsilon I}$ and $\left.\left\{\left(h_{n}{ }^{i}\right\}\right)\right\}_{n \geq 0, i \epsilon I} \rightarrow\left(h^{i *}\right)_{i \epsilon I}$.

Proof of Theorem 2: Let the Markov growth path dynamics sequences, $\left\{G_{n+1}^{i}\right\}_{n \geq 0, i \epsilon C}$, belongs to the compact and metric countries sequences set, $C=\left\{C_{i}\right\}_{i \in C}$. Then, the set $C$ admits a contraction mapping application sequences, i.e., an application sequences $\left\{g_{n}^{i}\right\}_{n \geq 0, i \in C}$ which takes values in knowledge sequences, $\left\{h_{n}{ }^{i}\right\}_{n \geq 0, i \epsilon C}$ for all $n \geq 0$ where $\left\{g^{i}{ }_{n}\left(h_{n}{ }^{i}\right)\right\}_{n \geq 0, i \epsilon C}=\left\{h_{n}{ }^{i}\right\}_{n \geq 0, i \epsilon C}$. Then, there exist a parameter, $\left\{\gamma\left(g_{n}^{i}\right)\right\}_{n \geq 0, i \in C \in}[0,1]$, such that $\left\{d\left(g_{n}^{i}\left(h_{n}{ }^{i}\right), g_{n}^{i}\left(h_{m}{ }^{i}\right)\right) \leq \gamma\left(g_{n}^{i}\right) d\left(h_{n}^{i}, h_{m}^{i}\right)\right\}_{n \geq 0, i \in C}$. Therefore, the compacity yields convergence, i.e., $\left.\left\{g_{n}^{i}\left(h_{n}{ }^{i}\right\}\right)\right\}_{n \geq 0, i \epsilon C} \rightarrow g^{i *}\left(h^{i *}\right\}_{i \epsilon C}$ since $\left\{h_{n}{ }^{i}\right\}_{n \geq 0, i \epsilon C} \rightarrow\left(h^{i *}\right)_{i \epsilon C}$ and $\left\{g_{n}^{i}\left(h_{n}^{i}\right)\right\}_{i \epsilon C, n \geq 0} \rightarrow g^{i *}$ and $\left(h_{n}^{i}\right)_{i \epsilon C, n \geq 0} \rightarrow h^{i *}$.

Example 3: Using the Banach fixed point theorem used above, convergence is similar to the existence and the stability of the equilibrium since knowledge spillovers increase continuously over time. Given two different times of the same growth rate path sequences, $m$ and $n$ such that $\left\{g_{n}^{i}\right\}_{n \geq 0, i \in C}$ and $\left\{g_{m}^{i}\right\}_{m \geq 0, i \in C}$ as well as the existence of $\left\{\varepsilon_{i}\right\}_{i \in C}>0$ and $\left\{\varepsilon_{j}\right\}_{j \in C}>0$, then all $m, n \geq N_{\varepsilon i}$, yields $\left\{d\left(g_{n}{ }^{i}\left(h_{n}{ }^{i}\right), g_{m}{ }^{i}\left(h_{n}{ }^{i}\right)\right) \leq\left(\varepsilon_{i}\right)_{i \epsilon l}\right.$ according to the growth rate path rates sequences. The same result holds for knowledge sequences, i.e., all $m, n \geq N_{\varepsilon i}$, such that $\left\{d\left(h_{m}{ }^{i}, h_{n}{ }^{i}\right) \leq \varepsilon_{i}\right\}_{n \geq 0, i \in C}$ and $\left\{d\left(h_{m}{ }^{j}, h_{n}{ }^{j}\right) \leq\left(\varepsilon_{j}\right)_{j \in C}\right.$ yields $\left\{d\left(g_{n}{ }^{j}\left(h_{n}{ }^{j}\right)\right.\right.$, $\left.g_{m}{ }^{j}\left(h_{n}{ }^{j}\right)\right) \leq\left(\varepsilon_{j}\right)_{j \in C}$. Indeed, the sequences, $\left\{g_{n}{ }^{i}\left(h_{n}{ }^{i}\right)=h_{n}{ }^{i}\right\}_{n \geq 0, i \in C}$, are Cauchy sequences and thus converge toward the steady state, $\left\{g^{i *}\left(h^{i *}\right)\right\}_{i \in C}=\left\{h^{i *}\right\}_{i \in C}$. Therefore, $i=1,2, \ldots, N$ yields the large number of law that $\sum_{i=1}{ }^{N}\left\{g^{i *}\left(h^{i *}\right)\right\}_{i \in C} / N=\sum_{i=1}{ }^{N} h^{i *} / N$ converges at $\left(g^{*}, h^{*}\right)$ since $\left.\left\{g^{i *}\left(h^{i *}\right)=h^{i *}\right\}\right\}_{i \in I}$ converge at the general equilibrium $\left(g^{*}, h^{*}\right)$. Therefore, knowledge spillovers provided by countries relationships through the network, I, reduces inequalities among countries. Also, it accelerate convergence and catching-up with the richest countries.

Theorem 2: Two different countries inside a given counties' block sequences are similar.

Proof: Given two countries inside the sequences block, $C=\left\{C_{i}\right\}_{i \epsilon l} \subset[0,1] \subset B(0,1), C$ belongs to a compact set, which is its growth path rate sequences. There exist $\left\{g_{n}{ }^{i}\right\}_{n \geq 0, i \in C}$ and $\left\{g_{n}{ }^{j}\right\}_{n \geq 0, j \in C}$ which respectively converge at $g^{i *}$ and $g^{j *}$ where $g=\left\{g^{k}{ }_{n}=G_{n+1}{ }^{k} / G_{n}{ }^{k}\right\}_{n \geq 0, k: i, j \in C} \rightarrow g^{k *}$ because of the closeness of $C$. Thus, those growth path rate sequences are Cauchy sequences and then any $\varepsilon^{k *>0}$ yields $n_{0} \in \mathbb{N}$ for two different times $m, n \in \mathbb{N}$. Also, locus where countries $i$ and $j$ are located, such that $n \geq n_{0}$ and $m \geq n_{0}$, yields $\left\{d\left(h_{n}{ }^{i}, h_{m}{ }^{j}\right) \leq\right.$ $\left.\varepsilon^{k *}\right\}_{n, m \geq 0, i, j \in C}$. Furthermore, by the continuity of the growth path rate, it yields $\left\{d\left(g_{n}{ }^{i}\left(h_{n}{ }^{i}\right), g_{m}{ }^{j}\left(h_{m}{ }^{j}\right)\right) \leq \varepsilon^{k * *}\right\}_{n, m \geq 0, i, j \in C}$ which means that the both countries $i$ and $j$ are similar. Moreover, by the fixed point theorem, the sequences, $\left\{g^{i}\left(h^{i *}\right)\right\}_{i \epsilon C}=\left\{h^{i *}\right\}_{i \in C} \subset C_{i}$ and $\left\{g^{j}\left(h^{j *}\right)\right\}_{j \in C}=\left\{h^{j *}\right\}_{i \epsilon C} \subset C_{j}$, admit fixed point limit of the sequences, $\left\{g^{k}\left(h_{n}^{k}\right)=h_{l}^{k}\right\}_{l=m, n \geq 0, j \in C}$. Since $\left\{h^{k *}\right\}_{k=i, j \in l} \subset\left\{B\left(h^{k *}, r^{k *}\right)\right\}_{k=I, j \in C}$, 
the closed ball sequences limit of $\left\{B\left(h^{k}{ }_{n}, r_{n}{ }^{k}\right)\right\}_{n \geq 0, k=i, j \in C}$, where $\left\{B\left(h^{k *}, r^{k *}\right) \supset g^{k *}\right\}_{k=i, j \in C}$, fixes the countries' sequences. This is such that they converge at the growth path rate equilibrium, $g^{k *}=\left(g^{i *}, g^{j *}\right)$ where $\left\{g_{n}{ }^{k}\right\}_{k=i, j \in C, n \geq 0} \rightarrow g^{k *}$. Thus, the growth path rate sequences is stable inside the whole network $I$, where the network general solution is given by $g^{*}$. Since convergence is expressed by $\left\{B\left(h_{l}^{k}, r_{l}^{k}\right)\right\}_{k=1 / 2(i+j) \epsilon C, l \geq 0} \rightarrow\left\{B\left(h^{k *}, r^{k *}\right)\right\}_{k=1 / 2(i+j) \epsilon C}$, then catching-up occurs if $(1 / 2)\left\{B\left(h^{k *}, r^{k *}\right)\right\}_{k=1 / 2(i+j) \epsilon C} \longrightarrow\left\{B\left(g^{*}\left(h^{*}\right), r^{*}\right)\right\} \subset C$. Countries $C_{i}$ and $C_{j}$ are similar because they belong to the same countries' sequences block, while $C$ is composed of several countries.

Theorem 3: Let the whole network $I$ of $R$ be divided into three countries blocks types by $r=D, E, H$, i.e., developing, emerging and industrialized countries respectively. Then the associated Markov growth path dynamics sequences or the $r$ countries blocks, $\left\{G_{n+1}^{r}\right\}_{n \geq 0, r \in I}$ move according to the velocity, $\left\{v_{n}^{r}\left(h_{r}{ }^{n}\right)\right\}_{n \geq 0, r \in I}$, which converge to $\left\{v^{r *}\right\}_{r \epsilon I}$. Since the countries blocks belong to the compact set, $I \subset R$, then each blocks growth rate paths sequences, $\left.\left\{g_{n}^{r}\left(h_{n}^{r^{*}}\right\}\right)\right\}_{n \geq 0, r \in I}$, converge at its respective equilibrium growth rate, $\left(g^{r *}\left(h^{r *}\right)\right)_{r \in I}$. Thereafter, the general equilibrium of the whole network $\left(g^{*}, h^{*}\right)$ exist in I such that $\left.\left\{g^{r^{*}}\left(h^{i^{*}}\right\}\right)=h^{i *}\right\}_{n \geq 0, i \epsilon I} \rightarrow g^{*}\left(h^{*}\right\}$ since $\left\{h^{i *}\right\}_{n \geq 0, i \epsilon I} \rightarrow h^{*}$.

Proof: The network $I$ is the set of all connected countries with heterogeneity based on the rate and level of GDP. According to the World Bank, they can be classified into three main categories which are developing, emerging, and industrialized countries depending on their per-capita income level, and thus their respective economic performance development level focused on technological change and speed. Also, according to the theory built, since stochastic growth paths expressed by the Markov sequences depending on time and space admits a growth path sequences, then using Lemma 1 to 4 and Theorem 1 and 2, the equilibrium exist. When taken separately, they are multiple, but also allow the average limit of the whole of them to converge at a unique limit or the general equilibrium which also is a fixed point due to the equivalency between knowledge and the economic growth path.

\section{Sudden Shocks in Connected Countries and Transmission Risks}

Assumption 2: The $r$ existing countries sequences blocks in $I$ growth path rate dynamics sequences, $\left\{g_{n+1}{ }^{r}\right\}_{n \geq 0, r \in I}$, move according to $\left\{g_{n+1}{ }^{r}=v^{r}{ }_{n} g_{n}{ }^{r}\left(h_{n}{ }^{r}\right)-\delta_{n}{ }^{r} s_{n}{ }^{r}\right\}_{n \geq 0, r \epsilon I}$. Here, $\left\{s_{n}{ }^{r}\right\}_{n \geq 0, r \epsilon I}$ is the idiosyncratic shock sequences, $\left\{\delta_{n}{ }^{r}\right\}_{n \geq 0, r \in I}$ is the severity of the idiosyncratic shock on the countries growth path sequences blocks, and $\left\{v^{r}\right\}_{n \geq 0, r \epsilon I}$ is the same thing for the speed associated to the growth path rate dynamics sequences.

Proposition 5: According to assumption 2, before the corona virus emergence, the r countries' economic performance highlighted by the growth 
path dynamics sequences and measured by the growth path rate sequences $\left(g^{\min }, g^{*}, g^{\max }\right)$ was such that, $g(D)=g^{\min }<g(E)=g^{*}<g(H)=g^{\max }$. Since $r=D, E, H$, then I exhibits multiple growth path rates equilibria.

Proof: According to assumption 3, if the dynamics sequences block is stable, i.e., converges at 0 , then $v^{r}{ }_{n} g_{n}^{r}\left(h_{n}{ }^{r}\right) \approx \delta_{n}{ }^{r} S_{n}{ }^{r}$. Therefore, the sequences, $\left\{g_{n}{ }^{r}\right\}_{n \geq 0, r \in I}$, converge at $\left\{\delta_{n}{ }^{r} S_{n}{ }^{r} / v^{r}\right\}_{n \geq 0, r \in I}$ Thus, at the boundary, $g^{*}$ converge at $\left(\delta^{*} s^{*}\right) / v^{*}$. Indeed, $\left\{g_{n}{ }^{r}\right\}_{n \geq 0, r=D, E, H \epsilon I} \rightarrow g^{r *}=\delta^{r *}\left(s^{r *} / v^{r *}\right)_{r=D, E, H \epsilon I}$ which is the equilibrium or the stable long-run growth, where $\left\{g_{n}{ }^{D}\right\}_{n \geq 0, D \epsilon I} \rightarrow \operatorname{Inf}(g)=g^{\min }<g^{*}, \quad\left\{g_{n}{ }^{E}\right\}_{n \geq 0, E \epsilon I} \rightarrow \operatorname{Inf}(g)=g^{*}<g^{\max }=\operatorname{Max}\left\{g_{n}{ }^{H}\right\}_{n \geq 0, H \epsilon I}$. Finally, the "corona virus" emergence yields $g^{v c *}$ existence such that there exist $\quad g^{r *}=(1 / 3) \Sigma\left\{g_{n}{ }^{r}\right\}_{n \geq 0, r=D, E, H \epsilon I} \rightarrow g^{r *}<g^{v C *}$. In addition, $g(D)=g^{\min } \geq g(E)=g^{*} \geq g(H)=g^{\max }$ are multiple equilibria.

Figure6: local stability of the growth path criteria

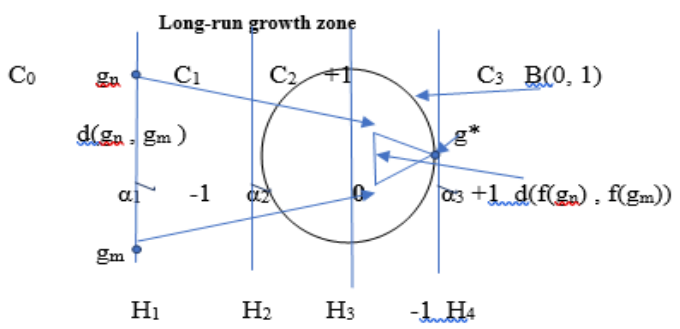

Figure 6 axis $x$ represents zones' heterogeneities in economic performance levels and axis $y$ is the frontier. Thus, this evocated the case of domestic remedy through which the unique stable equilibrium in growth sustainability exists.

Proposition 6: Let two countries' sequences blocks in I, i.e., $C=\left\{C_{k}\right\}_{k \in C}$ and $D=\left\{D_{l}\right\}_{l \epsilon C}$, be partners, where $C$ is initially endowed with the idiosyncratic shock sequences, $\left\{s_{n}{ }^{k}\right\}_{n \geq 0, k \in C}$. Thus, there exist an application sequences, $\left\{v p_{n}{ }^{r}\right\}_{n \geq 0, r \in I}$, defined on $C=\left\{C_{r}\right\}_{r \in I}$ and which allows the idiosyncratic shock transfer to $D$ to be expressed by $v c_{n}{ }^{l}\left(s_{n}{ }^{k}\right)=s_{n}{ }^{l} \epsilon D$ for all $n \geq 0$.

Proof: Let the countries sequences, $C=\left\{C_{k}\right\}_{k \in C}$ and $D=\left\{D_{l}\right\}_{l \in C}$, be connected partnerships in $I$. Here, the first countries' block inhabitants face the "corona virus" expressed by the sequences, $\left\{s_{n}{ }^{k}\right\}_{n \geq 0, k \in C}$, at time, $n$ where $k, l \geq 0$ are the regions number contain in those countries and expressed by the set, $C$ and $D$. After then, all the kinds of exchanges occur among than and yields a correspondence expressed by the application sequences $\left\{v p_{n}\right\}_{n \geq 0}$, such that all $\left\{s_{n}{ }^{k}\right\}_{n \geq 0, k \in C} \in C=\left\{C_{k}\right\}_{k \in C}$ yields $\left\{v p_{n}\left(s_{n}{ }^{k}\right)=s_{n}{ }^{l}\right\}_{n \geq 0,(k, l) \in C \times D}$. Indeed, $n \geq 0$, $\left\{s_{n}{ }^{l}\right.$ \}$_{n \geq 0, l \epsilon D} \epsilon D=\left\{D C_{l}\right\}_{l \epsilon D}$.

Stabilization Theorem 4: Let the whole existing countries sequences blocks in $I\left(C_{1}, C_{2}, \ldots, C_{M}\right)$ be compact sets with each endowed with shock 
sequences, $\left\{s_{n}{ }^{q}\right\}_{n \geq 0,1 \leq q \leq M}$. Thus, there exist an equilibrium in the shock $s^{*}$ such that $\left\{s_{n}{ }^{q}, v p_{n}\left(S_{n}{ }^{q}\right)=s_{n}{ }^{u}\right\}_{n \geq 0, q, u \in I} \rightarrow s^{*}$.

Where, $s^{*}=\left((1 / M) \sum_{1 \leq q \leq M, n \geq 0}\left(S_{n}{ }^{q}\right), 1 / M \sum_{n \geq 0,1 \leq q \leq M}\left(s_{n}{ }^{q}\right)\right)$

Proof: Let the whole $M$ countries sequences in the network, $I$ i.e., $\left(C_{1}\right.$ , $\left.C_{2}, \ldots, C_{M}\right)$ be all connected among them. Thus, using proposition 6 , $\left\{s_{n}{ }^{q}\right\}_{n \geq 0, q \in I}$ yields $\left\{v p_{n}\left(s_{n}{ }^{q}\right)=s_{n}{ }^{u} \in C_{j}\right\}_{n \geq 0, q, u \in I}$. Thus, there exist $\left\{s_{n}^{q}\right.$, $\left.v p_{n}\left(S_{n}{ }^{q}\right)=s_{n}{ }^{u}\right\}_{n \geq 0, q, u \in I}=B$ which is a matrix of format $(M, M)$ such that $\left\{s_{n}{ }^{q}\right.$, $\left.v p_{n}\left(S_{n}{ }^{q}\right)=s_{n}{ }^{u}\right\}_{n \geq 0, q, u \epsilon I} \rightarrow \mathrm{S}^{*}=\left(s^{q}, s^{u}\right)_{q, u \epsilon l}$ finally converges at:

$s^{*}=\left((1 / M) \sum_{1 \leq q \leq M, n \geq 0}\left(S_{n}{ }^{q}\right), 1 / M \sum_{n \geq 0,1 \leq q \leq M}\left(S_{n}{ }^{q}\right)\right)$

Therefore, the network system is stable.

\section{Risk Impact on the International Economy}

Theorem 5: Let a given country, $C_{k} \subset C=\left\{C_{r}\right\}_{r \epsilon l}$, be a convex set endowed with a idiosyncratic shock sequences, $\left\{s_{n}{ }^{k}\right\}_{n \geq 0, k \in C k}$,such that it converges to $s^{k *}=\operatorname{Max}\left\{s_{n}{ }^{k}\right\}_{n \geq 0, k \in C k}$. Here, $s^{k *}$ doesn't belong to $C_{k}$ and there exist an hyperplane. Also, $H^{k}$ separates the country $C_{k}$ from $s^{k *}$.

Proof: Convexity of the fixed country, $C_{k}$, means that given two regions of the country, i.e., $x, y \in C_{k}$, yields the existence of $\lambda$ such that $\lambda x+(1-\lambda) y \epsilon C_{k}$, i.e., $[x, y] \subset C_{k}$. Therefore, the same thing holds for the whole country due to sequences of the regions of the country, $C_{k}$. $\left\{x_{j}\right\}_{j k k}$ yields to a sequence, $\left\{\lambda_{k}\right\}_{k \in C k}$, such that $\Sigma \lambda_{k} x_{k} \subset C_{k}$. Consequently, the higher shock level, $s^{k *}$, exist but doesn't belong to $C_{k}$. By the separating hyperplane theorem, the following exists: $H^{k}$ an hyperplane which separates $s^{k *}$ from the whole country, $C_{k} \subset \mathrm{I}$ (see Figure 7 representing a space that includes a convex set and a separated point that allows the separation of the both by a hyperplane).

Lemma 7: Generalization of the Separating Hyperplane Theorem: In Theorem5, if the whole existing countries of the sequences block, $C=\left\{C_{r}\right\}_{r \in t}$, of the network I admits a shock sequences, $\left\{s_{n}{ }^{r}\right\}_{n \geq 0, r \in I}$, then $\left\{s_{n}{ }^{r}\right\}_{n \geq 0, i \epsilon I}$ converge to $\left\{s^{r *}\right\}_{r \in I}$ where $\left\{s^{r *} \cap\left\{\left\{C_{r}\right\}_{r \in I}=\varnothing\right.\right.$. Thus, there exist multiple hyperplane sequences, $\left\{H^{r}\right\}_{r \epsilon l}$, which separate $s^{r *}$ from all the existing countries' blocks in $I$.

Proof: According to Theorem 5, each convex countries' sequences, endowed with shock sequences, admits a hyperplane which separates the set from the average shock level when it is outside the set. Due to the validity of the process for $n$ existing convex countries' sequences in I, then, extending the property to $i=n+1$ countries' sequences, in order to validate the generalization of the hyperplane theorem, yield to the sum of 1 country admitting a hyperplane plus $n+1$ while others are doing the same thing. Then the $n+1$ convex countries sequences in I, i.e., $\left\{C_{1}, C_{2}, \ldots, C_{n}, C_{n+1}\right\}$, yield to $\left\{H^{i}\right\}_{i \epsilon(12 \ldots n)}$. Thereafter, the countries are separates among themselves, i.e., they are closed and networks are also closed. 


\section{IV.A. The Idiosyncratic Shock Dynamics Study} equilibria

Proposition 7: The idiosyncratic shock dynamics exhibits multiple

Proof: Let the idiosyncratic shock dynamics sequences, $\left.\left\{S_{n+1}{ }^{i}\left(d_{n}{ }^{i}\right\}\right)\right\}_{n \geq 0, i \epsilon I}$, be an increasing function of the death rate in each countries' sequences blocks, $\left\{C_{i}\right\}_{i \epsilon I}$. If the death rate sequences depend on the parameters sequences, $\left\{\delta_{s}^{i}\right\}_{n \geq 0, i \epsilon I}$, and, according to the data observations, if $\left\{\delta_{s}^{i}\right\}_{n \geq 0, i \epsilon I} \rightarrow 0$, then the countries' sequences $\left\{C_{i}\right\}_{i \epsilon}$ is composed of poor countries block since it yields $\left\{d_{n}{ }^{i}\right\}_{n \geq 0, i \epsilon I} \rightarrow d^{\min }=\operatorname{Inf}\left\{d_{n}{ }^{i}\right\}_{n \geq 0, i \epsilon I}$ and $\left\{S_{n}{ }^{i}\right\}_{n \geq 0, i \epsilon I} \rightarrow s^{\min }$. Otherwise, if $\left\{\delta_{n}{ }^{i}\right\}_{n \geq 0, i \epsilon I} \rightarrow 1$, then, in conformity to the data observations, the countries' sequences $\left\{C_{i}\right\}_{n \geq 0, i \epsilon I}$ is a rich countries' sequences block as $\left\{d_{n}{ }^{i}\right\}_{n \geq 0, i \epsilon I} \rightarrow d^{\max }$ $=\operatorname{Sup}\left\{d_{n}{ }^{i}\right\}_{n \geq 0, i \epsilon I}$. Here $\left\{s_{n}{ }^{i}\right\}_{n \geq 0, i \epsilon I} \rightarrow \mathrm{s}^{\max }$. Therefore, the death rate sequences, $\left\{d_{n}{ }^{i}\right\}_{n \geq 0, i \epsilon I} \rightarrow+\infty$. Finally, if $\left.\left\{\delta_{s}{ }^{i}\right\}_{n \geq 0, i \epsilon I} \rightarrow l \epsilon\right] 0,1\left[\right.$, then $\left\{s_{n}{ }^{i}\right\}_{n \geq 0, i \epsilon I} \rightarrow s^{*}$, which is the average level. Thus, $\left.s^{*} \epsilon\right] s^{\min }, s^{\max }$ [. The concerned countries' sequences are middle-income countries' block. Consequently, the death rate sequences, $\left.\left\{d_{n}{ }^{i}\right\}_{n \geq 0, i \epsilon I} \rightarrow L \epsilon\right] 0,+\infty$ [ (see the data provided in the appendix).

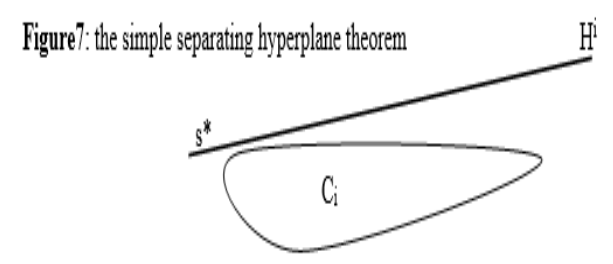

Proposition 8: Let the hyperplane sequences, $\left\{H^{i}\right\}_{i \epsilon I}$, be such that $\operatorname{Inf}\left\{H_{n}{ }^{i}\right\}_{n \geq 0, i \epsilon I}=H^{\min }$ and $\operatorname{Sup}\left\{H_{n}{ }^{i}\right\}_{n \geq 0, i \epsilon I}=H^{\max }$ exist. Thus, the isolation policy leads to death stabilization if the shock sequences impact on the economies is reducing over time due to some restrictions.

Proof: According to Proposition 7, each convex countries' sequences block is endowed with a shock sequences that admits an hyperplane sequences which separates the countries sets one to another as a barrage where from the maximum shock level, $\mathrm{s}^{*}$ is not reached in each countries' block sample. Indeed, since the multiple hyperplanes, $\left\{H^{i}\right\}_{i \epsilon(12 \ldots n)}$ separates all the $N$ convex countries sequences in I where $\cap\left\{C_{i}\right\}_{i \epsilon I}=\dot{\varnothing} i \epsilon I$ and $\left\{C_{i}\right\}_{i \epsilon I}$ are countries' sequences in the network, I. For all $i \epsilon\{1,2, \quad, N\}$, the whole hyperplane sequences are closed and bounded, thus, admitting an upper and a lower limits, $H^{\min }$ and $H^{\max }$. Here, $H^{\min }=\operatorname{Inf}\left\{H_{n}{ }^{i}\right\}_{n \geq 0, i \epsilon I}$ and $H^{\max }=\operatorname{Sup}\left\{H_{n}{ }^{i}\right\}_{n \geq 0, r \epsilon I}$, where $H^{*}=(1 / 2)\left(H^{\min }+H^{\max }\right)$ also exist. Then, each countries sequences block is endowed with his own idiosyncratic shock dynamics, $\left\{s_{n+1}{ }^{i}\right\}_{n \geq 0, i \epsilon I}$, moving separately from the other countries blocks with a low internal transmission only after the international closure of the network which, then, blocks the virus transmission. Indeed, two isolated forces can be identified. First is the epidemic transmission risk highlighted by the parameter included in the 
growth function which can stabilized, i.e., $\left\{\delta_{n}{ }^{i}\right\}_{n \geq 0, i \epsilon I} \rightarrow \delta^{i *}$. Thus, this yields $\left\{s_{n}{ }^{i}\right\}_{n \geq 0, r \epsilon l} \rightarrow s^{i *}$. Therefore, the growth rate sequences reaches its steady state, $\left\{g_{n}{ }^{i}\right\}_{n \geq 0, i \epsilon l} \rightarrow g^{i *}$. Second, if no prevention measures provided are followed by the population in order to fight the pandemic, specifically in high-death numbers countries, then $\left\{\delta_{s}{ }^{i}\right\}_{n \geq 0, i \epsilon I}$ may pursue its evolution and converge at its upper level, i.e., may reach $\delta^{\max }$ and yield $\left\{s_{n}{ }^{i}\right\}_{n \geq 0, i \epsilon I} \rightarrow s^{\max }$. Therefore, percapita income, $\left\{y_{n}{ }^{i}\right\}_{n \geq 0, i \epsilon I} \rightarrow \operatorname{Sup}\left\{y_{n}{ }^{i}\right\}_{n \geq 0, i \epsilon I}$, is caused by human being extinctions over time, since the death rate sequences $\left\{d_{n}^{i}\right\}_{n \geq 0, i \epsilon I} \rightarrow+\infty$ (thus tends to validate Thomas Malthus population theory).

Example 4: Given the death rates sequences caused by the pandemic shock, $\left\{d_{n}{ }^{i}\right\}_{n \geq 0, i \epsilon I}, M^{*}=\max \left\{d_{n}{ }^{i}\right\}_{n \geq 0, i \epsilon I}=d^{\max } \epsilon\left\{C_{i}\right\}_{i \epsilon I}$ and $m^{*}=\min \left\{d_{n}{ }^{i}\right\}_{n \geq 0, i \epsilon I}=d^{\min }$ $\epsilon\left\{C_{j}\right\}_{j \epsilon I}$ exist in the network I. Thus, if the countries' sequences remain connected, then $m^{*} \rightarrow M^{*}$ for all existing countries sequences in the network, I. Otherwise, if the countries' sequences are no more connected, then $m^{*}$ and M* are not linked with probability, where $p\left(m^{*}\right)=P\left(\left\{y_{n+1}{ }^{k}\right\}_{n \geq 0, k \epsilon I}\right.$. This is such that $\mathrm{y} \rightarrow y^{\min }$ since $\left\{C_{i}\right\}_{i \epsilon \epsilon}, n \geq 0, j, k \in I$ belongs to a low income countries' sequences. However, $p\left(M^{*}\right)$ is the probability for the countries' sequences to belong to the high income countries sequences category where $p\left(M^{*}\right)=P\left(\left\{y_{n+1}{ }^{k}\right\}_{n \geq 0, k \epsilon I}\right.$ since it concerns $\left\{C_{i}\right\}_{i \epsilon I, n \geq 0, j, k \epsilon}$, a high income countries' sequences block. For the emerging countries' sequences, $p^{*}$ exists such that $\mathrm{y} \rightarrow y^{*}$. Here, $p^{*}$ is the probability for the emerging countries' sequences category to transmit the epidemic to the other countries' sequences. Consequently, the sanitary policy is promoted by the global economy based on 2 levels: first, on international isolation, second, on internal isolation (crowded activities cease) expected results. First, this results make $p^{\max } \rightarrow p^{\min }$, i.e., $M^{*} \rightarrow m^{*}$, yields $\left\{s_{n}^{i}\right\}_{i \epsilon I, n \geq 0}$ $\rightarrow s^{*}=\left(M^{*}-m^{*}\right) / 2$ such that the number of deaths stabilize. Thus, the corona virus dynamics yields $\left\{d_{n}{ }^{i}\right\}_{n \geq 0, i \epsilon I} \rightarrow d^{*}=\left(d^{\min }+d^{\max }\right) / 2$ existence. Since $s^{*}$ once exist, $\left\{s_{n}{ }^{k}\right\}_{n \geq 0, k \in I} \rightarrow s^{*}$ yields $\left\{d_{n}{ }^{k}\right\}_{n \geq 0, k \epsilon I} \rightarrow d^{*}$, i.e., stabilization

Lemma 8: Countries classification in economic performance, termed under the international stabilization policy, yield multiple growth rate paths equilibria, $\left(g^{r}\right)_{r=i n f, *, \text { sup }}=\left(g^{\text {inf }}, g^{\prime} *, g^{\text {sup }}\right)$ respectively. This entails the lowest and the medium of the highest economic performance groups, i.e., $g^{\text {inf }}=\left\{\left(H^{\min }, s^{\min }, d^{\min }, y^{\min }\right), g^{*}=\left(H^{*}, s^{*}, d^{*}, y^{*}\right)\right.$, and $\left.g^{\text {sup }}=\left(H^{\max }, s^{\max }, d^{\max }, y^{\max }\right)\right\}$.

Proof: The hyperplanes sequences existence $\left\{H^{i}\right\}_{i \epsilon I}$, the sudden shock dynamics or the corona virus sequences $\left\{S_{n}{ }^{k}\right\}_{n \geq 0, k \epsilon I}$, and the death rates due to the corona virus $\left\{d_{n}{ }^{k}\right\}_{n \geq 0, k \epsilon I}$, as well as their respective per-capita income sequences $\left\{y_{n}{ }^{k}\right\}_{n \geq 0, k \in I}$, can be classified into three categories. This is indexed by $r$ as viewed above such that $r=$ low income countries, emerging countries, and industrialized countries. Also, the vector $\left(\left\{H^{i}\right\}_{i \epsilon I},\left\{s_{n}{ }^{k}\right\}_{n \geq 0, k \epsilon I},,\left\{d_{n}{ }^{k}\right\}_{n \geq 0, k \epsilon I}\right.$, $\left\{g_{n}{ }^{k}\right\}_{n \geq 0, k \epsilon I}$, ) then characterized the countries sequences blocks indexed by $r$ and the multiple equilibria $\left\{\left(H^{\min }, \sigma_{L}\right),\left(H^{*}, \sigma_{M}\right),\left(H^{\max }, \sigma_{H}\right)\right\}$. 
Here, $\sigma_{L}=\left(s^{\min }, d^{\min }, y^{\min }\right), \sigma_{M}=\left(s^{*}, d^{*}, y^{*}\right)$, and $\sigma_{H}=\left(s^{\max }, d^{\max }, y^{\max }\right)$ are the respective developing, emerging, and industrialized countries sequences blocks parameters.

Assumption 3: At each time, $n \geq 0$, the growth path dynamics equilibrium of the $r$ countries' sequences categories move such that, $\left\{G_{n+1}{ }^{r *}\right\}_{n \geq 0, r=(L, M, H)}=\left\{G_{n}^{r}\right\}_{n \geq 0, r=L, M, H}-\left\{\delta_{n}{ }^{r}{ }^{r}{ }_{n}\right\}_{n \geq 0, r=(L, M, H)}$.

Here, $\left\{\delta_{n}{ }^{r}\right\}_{n \geq 0, r=(L, M, H)} \geq 0$ is the impact of the virus on the human state of heath; $\left\{\mathrm{s}^{r}{ }_{n+1}\right\}_{n \geq 0, r=(L, M, H)}=\left\{\delta_{n}{ }^{r} \mathrm{~S}^{r}\right\}_{n \geq 0, r=(L, M, H)}=D_{n}{ }^{r}$ is the corona virus dynamics or the death movements; $\left\{G_{\mathrm{n}}^{r}\right\}_{n \geq 0, r=(L, M, H)}$ is the growth path sequences per-category, $r=L, M, H$ countries types.

Fundamental Theorem of the Theory: According to assumption 3, growth sustainability dynamics of each countries' category, $\left\{C_{r}\right\}_{r=L, M, H}$, with the growth path dynamics sequences $\left\{G_{n+1}{ }^{r}\right\}_{n \geq 0, r \in I}$ is in its reduced form, which is expressed by equation (1):

$g_{n+1}{ }^{r *}=\lambda_{n}{ }^{r} g^{r}{ }^{r}-\delta_{n}{ }^{r} d^{r}{ }_{n}$

Where $\quad\left\{g_{n+1}{ }^{r *}=G_{n+1}{ }^{r *} / G_{n}{ }^{r *}\right\}_{n \geq 0, r=L, M, H \epsilon I}=\left\{g_{n+1}{ }^{r} *\left(s_{n}{ }^{r}, g^{r}{ }_{n}\right)\right\}_{n \geq 0, r=L, M, H \epsilon I}$ and $r=$ inf or $L,{ }^{*}$ or $E$ and sup or $H$, are countries' sequences per-category; $n \geq 0$ is the current time; and $\lambda_{n}{ }^{r} \geq 0$ is the technological change level; and the country's sequences category are $r=L, M, H$.

Proof: According to assumption 3, the growth path dynamic $\left\{G_{n+1}{ }^{r}=G_{n}^{r}\left(S_{n}{ }^{r}\right)\right\}_{n \geq 0, r=L, M, H \in I}$; and according to proposition 7, the growth rate sequences, $\left\{G^{r}{ }_{n}\right\}_{n \geq 0, r=L, M, H}$, is the product of the growth rates and technological change per-sector, $\lambda_{n}{ }^{r}$ of the economy at time $n$, i.e., $\left\{G_{n}^{r}\right\}_{n \geq 0, r=L, M, H}=\left\{\lambda_{g}{ }^{r} g^{r}\right\}_{n \geq 0, r=(L, M, H)}$. Therefore, the corresponding growth path rate

sequences, $\left\{g_{n+1}{ }^{r *}=G_{n+1}{ }^{r} * / G_{n}{ }^{r}\right\}_{r=L, M, H}=\left\{g_{n+1}{ }^{r *}=g_{n+1}{ }^{r} *\left(s_{n+1}{ }^{r}, g^{r}{ }_{n+1}\right)\right\}_{n \geq 0, r=L, M, H}=\left\{\lambda_{g}{ }^{r} g^{r}\right\}_{n \geq 0,}$ $r=(L, M, H)$, exist. Here, the sequences, $\left\{S_{n}{ }^{r}\right\}_{n \geq 0, r=L, M, H}=\left\{\delta_{n}{ }^{r} \mathrm{~S}_{n}{ }_{n}\right\}_{n \geq 0, r=L, M, H}$, are thus linked to the growth rate path sequences such that $\left\{g_{n+1}{ }^{r *}=\lambda_{n}{ }^{r} g_{n}^{r}\right.$ $\left.\delta_{n}{ }^{r} d^{r}\right\}_{n \geq 0, r=L, M, H}$.

\section{The Social Planner's Intervention}

Fundamental Linear Theorem: Let the linear programming problem, $\left\{P^{r}\right\}_{r}$, be such that $\left\{P^{r}\right\}_{r=L, M, H}=\operatorname{Max}\left\{\Delta y_{n}{ }^{r}=\Gamma\left\{\Delta\left(G_{n}{ }^{i} / D_{n}{ }^{r}\right)\right\}_{n \geq 0, i \in I}\right.$ for all the countries sequences types, $\left\{C_{r}\right\}_{r=i n f, *, \text { sup, } n \geq 0}$ where, $\left\{\Delta y_{n}{ }^{r}\right\}_{n \geq 0, r \in I}$ is per-capita income, $\left\{D^{r}\right\}_{i \epsilon l, r=i n f, *^{\prime}, \text { sup }, n \geq 0}$ is the sequences of the death recorded and, $\left\{G_{n}{ }^{r}\right\}_{r=i n f, * ', s u p, n \geq 0}$ is the growth path sequences measured by the GDP. Then, sustainable growth equilibrium, $\left(G^{*}, D^{*}\right)$ existence yields, the linear programming problem, $\left\{\mathrm{P}^{r}\right\}_{r}$, admits the equilibrium sequences of optimal per-capita income, $\left\{\Delta y^{r *}\right\} \quad r=i n f, *^{*}$, sup,$n \geq 0$ such that, $\left\{\Delta y^{r *}\right\}_{r=i n f, *^{\prime}, \text { sup }, n \geq 0}$ $=\operatorname{argmax}\left\{\Delta y_{n}{ }^{r}=\Gamma\left\{\Delta\left(G_{n+1}{ }^{i} / D_{n+1}{ }^{i}\right)\right\}_{r=i n f,{ }^{\prime}, \text { sup }, n \geq 0}\right.$ 
Proof : From the resolution theorem, the linear programming sequences, $\left\{P^{r}\right\}_{r=L, M, H}$, consists of the optimization of the ratio of the growth path and death sequences, i.e., $\left\{P^{r}\right\}_{r=L, M, H}=\operatorname{Max}\left\{\Gamma\left\{\Delta\left(G_{n+1}{ }^{i} / D_{n+1}{ }^{i}\right)\right\} \rightarrow\left\{\Delta y^{r}=\left\{\Delta\left(G^{r} / D^{r}\right\}\right)\right\}_{r=L, M, H I}\right.$.

Here, $\left\{G^{r}\right\}_{r=L, M, H \epsilon I}$ is a sequences of polytope sets of the GDP growth rate measurable sequences. For $\left(G_{n+1}^{i}\right)_{n \geq 0, i \epsilon I},\left(G_{n+1}\right)_{n \geq 0, i \epsilon I} \rightarrow\left\{G^{r}\right\}_{r=L, M, H \epsilon I}$. Death sequences, $\left\{D^{r}\right\}_{r=L, M, H}$, is a sequences of cones such that the shock impact measurable by the deaths number, $\left(D_{n}^{i}\right)_{n \geq 0, i \epsilon I}$, at each period converge, i.e., $\left(D_{n}^{i}\right)_{n \geq 0, i \epsilon I} \rightarrow\left\{D^{r}\right\}_{r=L, M, H \epsilon I}$. Through the concavity and the convexity of the objective function, $\Gamma\left\{\left(G_{n+1}{ }^{i}, D_{n+1}{ }^{i}\right)\right\}_{n \geq 0, i \epsilon I}$, respectively in the first argument and in the second argument, the sequences, $\left\{P^{r}\right\}_{r=L, M, H}$, admits at least one extreme sequences solution, $\left(G^{r}, D^{r}\right)_{r=L, M, H}$. Here, $\left\{G^{r}\right\}_{r=L, M, H}$ is a convex hull sequences of the extreme points solution of the linear programming sequences and $\left\{D^{r}\right\}_{r=L, M, H}$ is a cone sequences of the extreme points of the linear programming sequences, $\left\{P^{r}\right\}_{r=L, M, H}$. Since $\left\{G^{r}\right\}_{r=L, M, H} \in\left\{P^{r}\right\}_{r=L, M, H}$ for a fixed death stock is a concave function, it is expressed by the product of technological change and the respective growth rates of all the existing economic sector, i.e., it is an increasing function. In contrast, $\left\{D^{i}\right\}_{i \epsilon l}$, a nonnegative linear combination of the extreme rays sequences, is a decreasing function and the both sequences meet at least once on the space. Here, percapita income sequences, $\left\{\Delta y^{r *}=\Delta\left(G^{r *} D^{r *}\right)\right\}_{r=L, M, H}$, is the corresponding ratio. Therefore, given the sequences, $\left\{e_{n}{ }^{r}\right\}_{n \geq 0, r=L, M, H}$ and $\left\{r_{n}^{r}\right\}_{n \geq 0, r=L, M, H}$ respectively of $\left\{G^{r *}\right\}_{r=L, M, H}$ and $\left\{D^{r *}\right\}_{r=L, M, H}$, the sets of the extreme points of $\left\{G^{i^{*}}\right\}_{i \epsilon I}$ and of the extreme rays of $\left\{D^{k}\right\}_{k \epsilon I}$ yields $\left\{G^{i *}\right\}_{i \epsilon I}=\operatorname{Max}\left\{G_{n+1}{ }^{i}\right\}_{n \geq 0, i \epsilon I} \rightarrow\left\{G^{r *}\right\}_{r=L, M, H} \quad$ and $\quad\left\{D^{i *}\right\}_{i \epsilon I}=\operatorname{Min}\left\{\delta_{s}{ }^{i} D_{n}{ }^{i}\right\}_{n \geq 0, i \epsilon I}$ $\rightarrow\left\{D^{r *}\right\}_{r=L, M, H}$. Indeed, $\left\{P^{r}\right\}_{r=L, M, H}$ admits the optimal solution sequences, $\left\{G^{r *}, D^{r *}\right\}_{r=L, M, H}$.

Here,

$\left(\mathrm{G}_{n+1}\right)_{n \geq 0, i \epsilon I}=\left\{\Sigma_{t=0}{ }^{t=+\infty} \lambda_{t} e^{t}-\sum_{t=0}{ }^{t=+\infty} \mu_{k} r_{k}\right\}_{t \geq 0} \rightarrow\left\{G^{r *}\right\}_{r=L, M, H}$

$\left(\mathrm{D}_{n+1}{ }^{i}\right)_{n \geq 0, i \epsilon I}=\left\{\Sigma_{t=0}{ }^{t=+\infty} \mu_{k} r_{k}=\left\{\delta_{n}{ }^{i} D_{n}{ }^{i}\right)\right\}_{t \geq 0, i \epsilon I} \rightarrow\left\{D^{r *}\right\}_{\mathrm{r}=\mathrm{L}, \mathrm{M}, \mathrm{H}}$

Where $\lambda_{t} \geq 0, \mu_{k} \geq 0$ for all $t, k \geq 1$ and $\Sigma_{t=0}=+\infty \lambda_{t}=1$

Finally, since $\quad\left\{G^{r *}, D^{r *}\right\}_{r=L, M, H \rightarrow} \rightarrow\left\{G^{*}, D^{*}\right\}, \quad$ then $\left.\left\{\Delta y^{r *=} \Delta\left(G^{r *} / D^{r *}\right)\right\}_{r=L, M, H} \rightarrow \Delta y^{*}=\Delta\left(G^{*} / D^{*}\right)\right\}$. Indeed, $\left\{P^{r}\right\}_{r=L, M, H}$ admits the equilibrium solution sequences, $\left\{G^{*}, D^{*}\right\}_{r=L, M, H}$, that yields growth sustainability since it yields to the optimal per-capita income equilibrium variation, $\Delta y^{*}$.

\section{Numerical Experiments of the Theory: Updating Statistics on the Corona Virus Pandemic until January 2021 Equation (1) Numerical Experiment}

Let $r$ be such that $r=L, M, H$, where $\lambda_{g}{ }^{r}$ is per-countries' category, $\mathrm{r}$ knowledge spillovers and $\delta_{n}{ }^{r}$ per-countries' category corona virus severity of 
the sample r. Also, $\Sigma_{\mathrm{r}} \lambda_{g}{ }^{r}=1$ means that the countries' sample is highlighted according to knowledge spillovers importance. Thus, $\Sigma_{r} \delta_{n}{ }^{r}=1$ in each sample. According to setting, $D$ is for developing countries sample, $E$ for emerging countries sample, and $H$ is for industrialized countries sample. The equilibrium dynamics of the economy or future growth rate, $g_{n+1}{ }^{r *}$, moves according to the difference between the economic growth knowledge spillovers and the corona virus impact in a given country of the sample. Also, $r$ highlights the product of the deaths rate, $d^{r}$, as stipulated by equation (1). Thus, Table 3 shows the countries' growth rates augmented by knowledge spillovers. Indeed, growth without shock, $\left\{g=\lambda_{g}{ }^{r} g^{r}\right\}_{r=H, E, D}$, results from data observed in 2019. Thereafter, the dynamics evolution of the growth rate, including the "corona virus" shock $\left(g_{n+1}{ }^{r *}\right)_{r=H, E, D}$, is as a result of the model computation. Tables 3, 4, and 5 graphical presentations are displayed by Figure 8, 9, and 10 respectively for the developed, the emerging, and the developing countries (see the appendix section).

Proposition 9: Corona virus yields economic growth decrease all around the world (see Figure 8 and the association numerical experiment data in the appendix section for proof)

Figure 8. Growth in the world before (at t) and under corona virus (at $t+1$ )

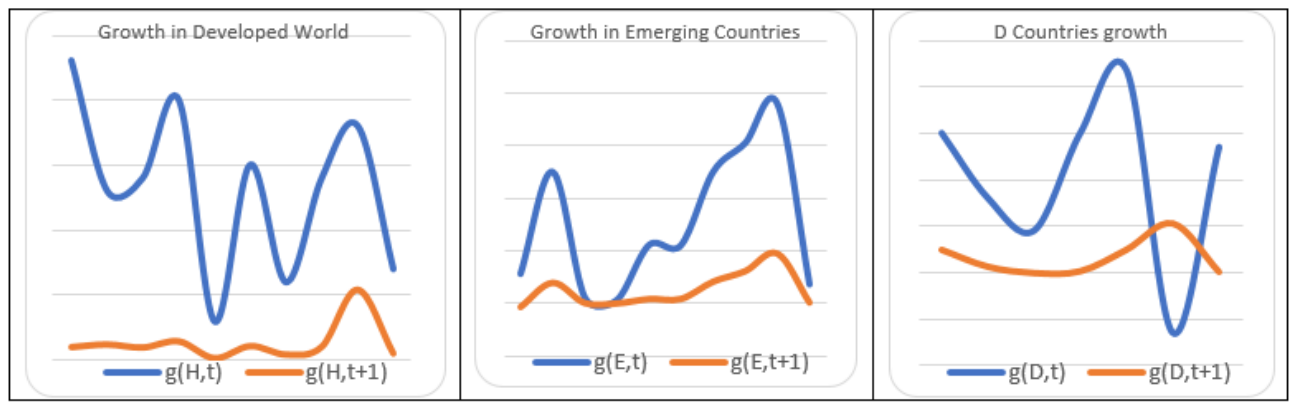

Figure 8 explanation: First, since $\delta_{n}{ }^{H, i}=\mathrm{vc}_{\mathrm{t}}^{\mathrm{H}, \mathrm{i}} / \Sigma_{\mathrm{i}=1}{ }^{10} v c_{t}^{H, i}=6438602$ and $\lambda_{g}{ }^{H i}=g_{n}{ }^{H, i} / \Sigma_{i=1}{ }^{10} g_{n}{ }^{H i}=13,3, \Sigma \delta_{n}{ }^{H, i}=1, \Sigma \lambda_{g}{ }^{H i}=1, v c_{t}{ }^{H, i}$ is the virus detected cases data sample, and $D_{t}^{H}$ is the deaths number recorded in developed countries. Second, since $\delta_{n}^{E, i}=v c_{t}^{E, i} / \Sigma_{i=1}{ }^{10} v c_{t}^{E, \mathrm{i}}=5416265$ and $\lambda_{g}{ }^{E i}=\mathrm{g}_{\mathrm{n}}{ }^{\mathrm{E}, \mathrm{i}} / \Sigma_{\mathrm{i}=1}{ }^{10} \mathrm{~g}_{\mathrm{n}}{ }^{\mathrm{Ei}}=13,3$, $\Sigma \delta_{n}{ }^{E i}=1, \Sigma \lambda_{g}{ }^{E i}=1, v c_{t}^{E, i}$ are the observed virus detected cases data, and $\mathrm{D}_{\mathrm{t}}$ is the deaths number recorded in emerging countries. Third, since $\delta_{n}{ }^{D, i}=v c_{t}{ }^{D, i} / \Sigma_{i=1}{ }^{10} v c_{t}{ }^{D, i}=29159 \quad$ and $\quad \lambda_{g}{ }^{D i}=g_{n}{ }^{D, i} / \Sigma_{i=1}{ }^{10} g_{n}{ }^{D i}=13,3, \quad \sum \delta_{n}{ }^{D i}=1$, $\Sigma \lambda_{g}{ }^{D i}=1$, and $D_{t}^{D, i}$ is the deaths number recorded and are the observed virus detected cases data in developing countries.

The theory provided displays Figures 8,9 , and 10 as a single onenumbered. Figure 11 (where axis $x$ relates the date and axis $y$ relates the growth dynamics) relates the history. 


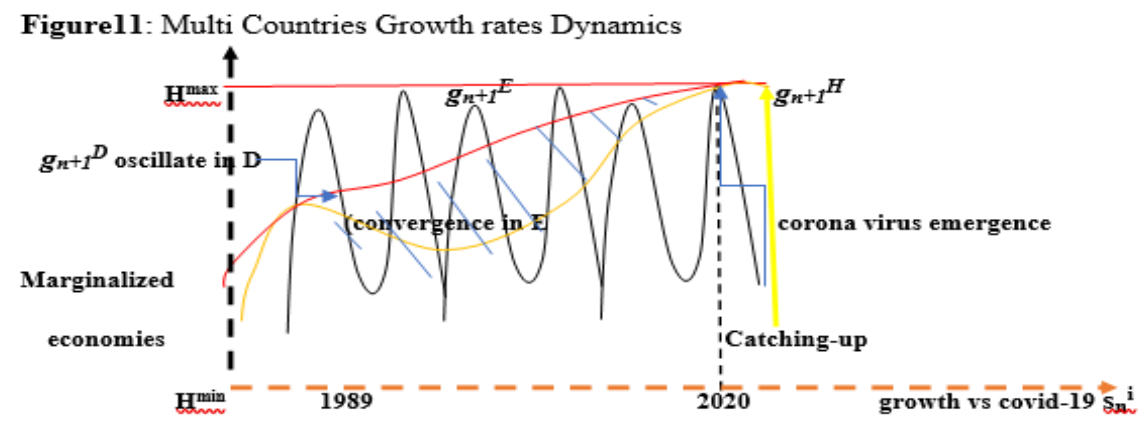

\section{Discussions}

From 1989s until today, the least developed countries' economy aims to converge toward market-based economy after the Berlin Wall Fall, the Communism, and the cold war ceases. This symbolizes the victory of the liberal economy because the planned Soviet Union model has been given up almost everywhere. This is as a result of market-based economy which is focused on competitive markets' power. Also, the East and the West Germany succeeded its transition and Russia also caught up with most industrialized countries' economic performance. Furthermore, Russia is currently classified at the $8^{\text {th }}$ rank of the most richest countries. However, economic retarded countries or marginalized countries still exist. Thus, situation needs to be addressed through the networks association for exchange of knowledge purpose. The countries which are trying to improve their economic levels are assumed to be in transition toward market-based economy. In parallel, the Emerging countries have already successfully achieved their convergence stage, and they have mostly experienced improvement in their economic growth both in level and rate through knowledge investment and spillovers. However, before the years 2000s, only the 4 Asian dragons' countries successfully transited from an under developed to developed countries, i.e., Hong-Kong, Singapore, South Korea, and Taiwan successfully converge toward the industrialized countries' economic growth path. This was achieved through knowledge copy and assimilation, as well as exchange of trade based on knowledge spillovers. Therefore, there are no more considered as developing countries, but they have rather settled between the most richest and the emerging countries that are richer. From the years, 2000s, until today, China emerges and mostly shares its knowledge with the least advanced countries, specifically African countries, pushing Washington Consensus fall for Pekin Consensus emergence in least advanced countries. Here, transition towards market-based economy remains the goal looked forward by the integrated economies.

Next section introduces the social planner's intervention which aims to establish the optimality of the equilibrium if it exists under the corona virus 
context. In this case, the main question remains how to eradicate the pandemic. The Pareto-optimal equilibrium $\left(G^{*}, D^{*}\right)$ is focused on using the linear programming method rather than the traditional method settled on convexity and optimization technique, which is commonly used in growth theory. Thereafter, the theorems provided prove of the existence of a solution of the social planner optimization problem based on the linear programming method. Moreover, since the countries' growth path sequences follow the Markov process, such that they depend positively on knowledge, but negatively on the corona virus shock impact, the two opposite forces interaction determine the following. First, knowledge generates wealth; second, corona virus generates deaths; and the conjunction of the both forces ruled out growth sustainability.

Assumption 4: High death number $\left\{D_{n}^{r}\right\}_{i \epsilon l, r=i n f, *, \text { sup }}>0$ reduces population size, $\left\{N_{n}^{r}\right\}_{n \geq 0, r=i n f,{ }^{*}, \text { sup }}$ then yields the difference decrease, i.e., $\left\{\Delta N_{n}^{i}=N_{n}^{i}-D_{n}^{i}\right\}_{i \epsilon l, r=L, M, H}=\left\{N^{i}\right\}_{r=L, M, H, i \epsilon l}<\left\{N_{n}^{i}\right\}_{r=L, M, H i \epsilon l}$. Therefore, per-capita

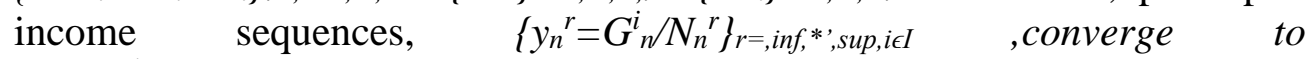
$\left\{y_{n}{ }^{r}=G_{n}^{i} / D_{n}^{r}\right\}_{r=i n f, *, s u p, n \geq 0}$, i.e., increases with corona virus action.

\section{The Social Planner's Numerical Experiments}

The general equilibrium, $\left\{\Delta y^{r *=} \Delta\left(G^{r *} / D^{r *}\right)\right\}_{r=L, M, H}$ sequences is computed using data observations on per-capita income of the World Bank, 2019, as well 2020 data and based on the corona virus. Thus, deaths and detected cases converted in \% is denoted by $d t$ of 2020 . Here, the ratio of deaths per country of the whole given countries' category sample is set to 1 . Data provided by the theory applied to real data observations are displayed in Figure 9, which is per-capita income without the virus. This took place in 2019 before the beginning of the pandemic and per-capita income, and it is divided into three categories. Income variables are given as $g / d t$, i.e., the ratio of the growth rate and the death rate. Since income variations are $100(\mathrm{~g} / \mathrm{dt})$, thus, future per-capita income equals the sum of per-capita income and per-capita income variations in level. Then, numerical experiments highlighted by Figure 9 show the countries' mutations on per-capita income without the virus, $y(r, t)$, and under the virus action, $y(r, t+1)$.

Proposition 10: The virus yields per-capita income increase in the stable way in developed countries, while inverted U-shape curve quickly settled in the developing world but is slowly half settled in the emerging countries (see Figure 9 and the associated numerical data tables in the appendix for proof). 
Figure 9. The world per-capita income

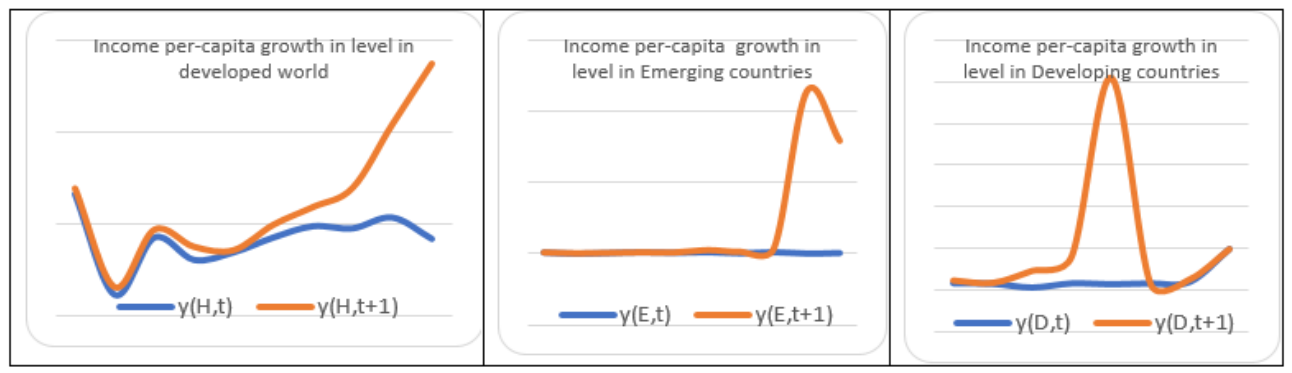

Therefore, according to our sample, per-capita income variations due to the deaths caused by corona virus are: $\Delta y^{H *}=0.350 / 10=0.035=3.5 \%$, $\Delta y^{E *}=0.416 / 10=0.041=4.16 \%, \quad$ and $\quad \Delta y^{D *}=0.12 / 10=0.012=1.2 \%$. Consequently, the unique equilibrium in income variation is $\Delta y^{*}=(3.5+4.16+1.2) / 3=0.012=2.95 \%$ (see Figure 12 )

Table 2. World Bank Countries' classification according to per-capita average income in 2019

\begin{tabular}{|l|l|l|l|l|}
\hline 2019 & $y_{1}$ & $y_{2}$ & $\mathrm{y}_{3}$ & $y_{4}$ \\
\hline Range & $<1,026$ & {$[1,026 ; 3,995]$} & {$[3,995 ; 12,375]$} & $\geq 12,375$ \\
\hline
\end{tabular}

Where $y_{1}$ is per-capita income of the low-income countries, $y_{2}$ is percapita income of the lower-middle income countries, $y_{3}$ is per-capita income of upper-middle income countries, and $y_{4}$ is per-capita income of high income countries. In this article, we consider developing countries and per-capita income to be such that $y_{D}<1,026$. As stipulated by the World Bank, the emerging countries is approximately the average of both ranges, i.e., $y_{E}$ $\epsilon[1,995 ; \& 11,000]$. Also, the industrialized countries per-capita income is given as $y_{H} \geq 11,000$. Thus, deaths due to corona virus yields per-capita income increase as viewed above. This modifies the WB levels such that the $\mathrm{D}$ countries and per-capita income becomes $y_{3}{ }^{6}=\Delta \mathrm{y}^{\mathrm{H}}+y_{1} \leq 1,026+0.012=1,038$, i.e., $y_{3}{ }^{`} \leq 1,038$. For the second category known as countries $\mathrm{E}$, we added 0.041 . Therefore, taking the average divided by 2, added to 0.020 , yields $y_{2}{ }^{6}=\Delta \mathrm{y}^{\mathrm{E}}+y_{2} \boldsymbol{\epsilon}\{[1,026+0.2,3,995+0.2[+[3,995+0.2,12,375+0.2[\}=\{[1,226$, $4,195\left[+\left[4,195,12,575[\}=\left[1,226,12,575\left[\right.\right.\right.\right.$. Thus, $y_{2}{ }^{6}=[1,226,12,575[$. Finally, for the countries, $H$, we have $y_{1}{ }^{`} \geq 12,375+\Delta \mathrm{y}^{\mathrm{H}}=12,375+0,035=12,410$. Thus, $y_{1}{ }^{\circ} \geq 12,410$.

Consequently, the opening of the countries for exchange is one of the economic growth engine. Otherwise, if frontiers' separability is maintained, then it would yield multiple equilibria rather than the group equilibria studied before, which rules out all the effort made for globalization to emerge ${ }^{1}$ (see

${ }^{1}$ Since each countries' sequences set $\mathrm{C}=\left\{C_{i}\right\}_{i \epsilon I}$ in a $I$ network, exchanges, yield follower countries and receive knowledge spillovers, it transits toward a market-based economy (middle-income countries) or converge (emerging countries) toward more advanced 
Figure 6). Thus, this remains the necessity for countries to keep being connected, since going back is later and no more possible due to high-tech connections supports around the world between people, i.e., internet and other social supports contacts (Facebook, Twitter, Linkedin,...). The focus is to maintain contacts and continue to develop the communication process because it has more advantages than the contrast. Hence, protection techniques against sudden negative shocks make perturbations emergence to be understood, thereby improving the networks functioning for the future of humanity.

\section{The Macro-economics' Empirical View of the Theory Presentation of the Study Consequences}

Proposition 11: Before the virus came, the world equilibrium, symbolized by the inverted U-shape curves, and the sustainable growth signal reversed after high growth oscillation, specifically in developing and emerging countries (see Figure 12 below and the associated data in the appendix for proof)

Figure 12. The world countries growth rates variations

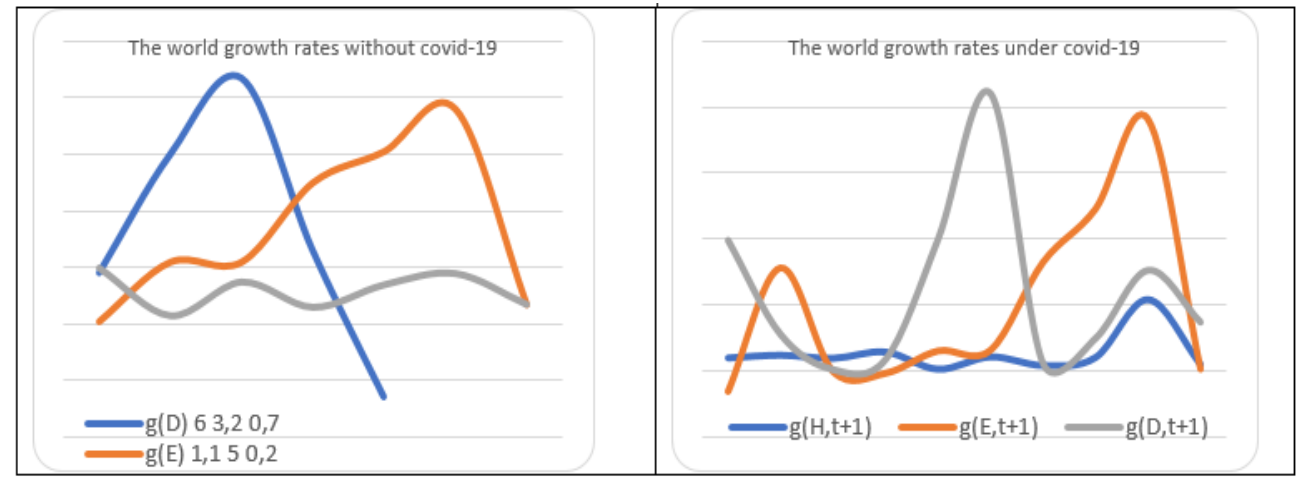

Proposition 12: Before the virus came, developing income inequalities were greater around the world followed by the emerging countries, the sudden corona virus shock, and reduction in income inequalities everywhere in the three world blocks. Thus, the new equilibrium is characterized by stability in the developed world and sudden boost in emerging countries in contrast to a low increase in the developing world (see Figure 13 below).

economies, and may catch-up the industrialized countries (Russia and the 4 Asian Dragons). Here, marginalized countries are those located outside of the network, I. 
Figure 13. The world countries income variations

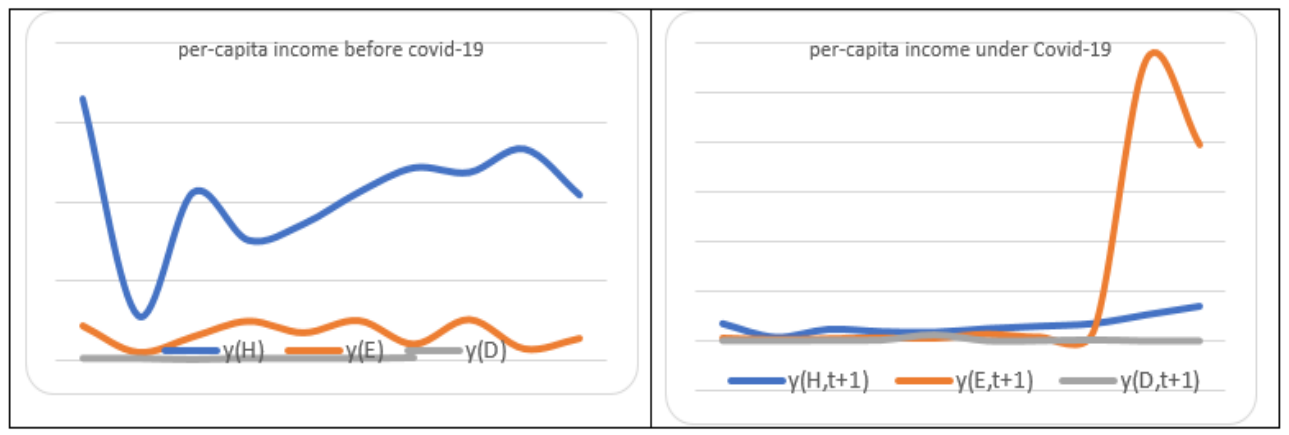

Definition 4: The world economy is globalized when a unique stable equilibrium exist, $\left(g\left(r^{*}, t\right), g\left(r^{*}, t+1\right), y\left(r^{*}, t\right), y\left(r^{*}, t+1\right)\right)$, which is provided by the theory and can be proved numerically.

Proposition 13: There exist a unique stable numerical equilibrium, $\left(g\left(r^{*}, t\right), g\left(r^{*}, t+1\right), y\left(r^{*}, t\right), y\left(r^{*}, t+1\right)\right)$, allowing the three countries' economies blocks similarity

Proof: The existence of the numerical equilibrium is provided by: $g\left(r^{*}, t+1\right)=1 / 3 \sum_{r=D, E, H} g(r, t+1)=$ where $g(r, t)=1 / 3 \sum_{r=D, E, H} g(r, t)=$ $y\left(r^{*}, t+1\right)=1 / 3 \sum_{r=D, E, H}=y(r, t+1)=$ where $y(r, t),=1 / 3 \sum_{r=D, E, H} y(r, t)=$ Then the unicity of the computational equilibrium is provided by $g\left(r^{*}, t\right)$ such that, $g(r, t)=1 / 3 \sum_{r=D, E, H} g(r, t)=1 / 3\left(1 / 10 \sum g(D, t)+1 / 10 \sum g(E, t)+1 / 7 \sum g(H, t)\right)$ $=1 / 3\left(1 / 10 \sum g(D, t)+1 / 10 \sum g(E, t)+1 / 7 \sum g(H, t)\right)$

Figure 13. The empirical globalized equilibrium is a space endowed with several frontiers (y axis), and each is composed of a center, $g(j, t)_{j=D, *, H}$, and a radius with an unknown length indicating existing frontiers among heterogeneous countries in economic performance

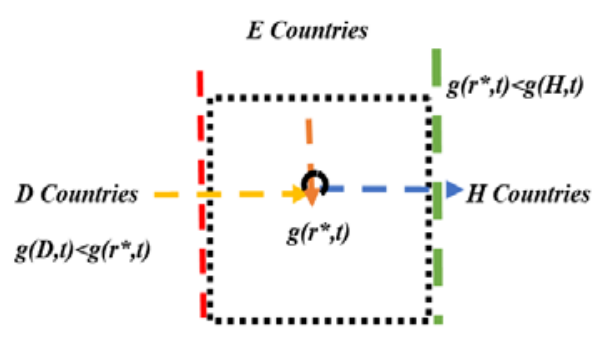

\section{Conclusion}

In conclusion, this paper focuses on the recent shock that took place all over the world, the corona virus pandemic, specifically its relation to growth and income. We introduced countries first and wonder, after, what happens about converges and catching-up desired in the economic globalization context through a mathematical model based on the economic growth that is submitted to numerical experiments after in two steps. The first concerns private agent's behavior and the social planner after when countries are fixed in general. When classified into three blocks, the study reveals 
growth decrease specifically in developed countries since the virus had more impact on rich countries compared to the emerging countries as well as the developing countries. At that step, developed countries' growth path then moves slowly because the virus yields marginal decreasing capital productivity. This is like the first growth models where convergence yields equality among countries in development terms. Poor countries experienced growth faster than the rich countries but this was only temporary since vaccines are going to be used. However, before the vaccines would be distributed to the developed world, the emerging countries' economies will be less affected by the pandemic compared to the developed world during the pandemic eradication process.

\section{References:}

1. Acemoglu, D. \& Ventura, J. (2002). The world income distribution, Quarterly Journal of Economics 117, 659-694.

2. Aghion, P. \& Howitt, P. (1992). A Model of Growth Through Creative Destruction, Econometrica, 60, 323-351.

3. Arrow, K.J. (1962). The Economic Implications of Learning by Doing, Review of Economic Studies, 29(1), 155-173.

4. Arroyo, C. R., Dinopoulos, E. \& Donald, S.G. (1994). Schumpeterian Growth and Capital Accumulation, Unpublished

5. Azariadis, C. \& Drazen, A. (1990). Threshold Externalities in Economic Development, Quarterly Journal of Economics.

6. Becker, G. (1964). Human Capital, Columbia University Press.

7. Cavalcanti, T. \& Giannitsarou, C. (2012). Network structure and human capital dynamics, Working Paper, University of Cambridge.

8. Chou, S. Y., Grossman, M. \& Saffer, H. (2003). An Economic Analysis of Adult Obesity Results from the Behavioral Risk Factor System, Journal of Health Economics, 23(3), 565-587.

9. Denison, E.F. (1962). The Sources of Economic Growth in the United States, New-York Committee for Economic Development

10. Dixmier, J. (1981). General Topology, France University Press

11. Elliott, M. \& Golub, B. (2017). A Network Approach of Public Goods, Harvard University Press.

12. Eicher, T. (1996). Interaction Between Human Capital and Technological Change, Review of Economic Studies, 63, 127-144

13. Fogli, A. \& Veldkamp, L. (2011). Germs, social networks and growth, mimeo, University of Minnesota.

14. Gagnon, J. \& Goyal, S. (2017). Networks, Markets and Inequality, American Economic Review, 107 (1), 1-30.

15. Harrod, R. (1939). An Essay in Dynamic Theory, Economic Journal, 49, $14-33$ 
16. Howitt, P. (2000). Endogenous growth and cross-country income differences, American Economic Review 90, 829-846

17. Kremer, M. \& Glennester, R. (2004). Strong Medicine and Creative Incentives for Pharmaceutical Research on Neglected Diseases, Princeton University Press

18. Lindner, I. \& Strulik, H. (2012). From Tradition to Modernity: Economic Growth in a Small World, Discussion Paper, University of Hannover

19. Lindner, I. \& Strulik, H. (2014). The Great Divergence: A Network Approach, Discussion Paper, TI 2014-033/II, University of Hannover

20. Loubaki, D. (2012a). On the Mechanics of the Diseases Reduction in Poorest Developing Countries, Journal of Economics and Sustainable Development, 3 (8), 37-51

21. Lucas, R.E. (1988). On the Mechanics of Economic Development, Journal of Monetary Economics, 22 (1), 3-42

22. Lucas, R.E. (2000). Some Macroeconomics for the 21st century, Journal of Economic Perspectives 14, 159-168.

23. Lucas, R.E. (2009). Trade and the industrial revolution, American Economic Journal: Macroeconomics, 1, 1-25.

24. Philipson, T. J. \& Posner, R.A. (1999). The Lonh-Run Growth in Obesity as a Function of Technological change, W.P. 7423, National Bureau of Economic Research

25. Romer, P.M. (1986). Increasing Returns and Long-Run Growth, Journal of Political Economics, 94 (5), 1002-1037

26. Solow, R. (1956). A Contribution to the Theory of Economic Growth, Quarterly Journal of Economics, 70 (1), 65-94

27. Stockey, N. (1988). Learning by Doing and the Introduction of New Goods, Journal of Political Economy, 96, 701-708

28. Zon, A. \& Myusken, J. (2001). Health and Endogenous Growth, Journal of Health Economics, 20, 169-185.

\section{Online Publication, Annex}

Data on corona virus recorded through observations classified according to the theory proposed: $r=$ developing countries (D), emerging countries (E), industrialized countries (H). Here DC means detected cases and DN means deaths number, Data Source: SARS-COV-2 corona virus. Thus, through the calculus, we can determine both variables and parameters necessary for applying the theory to build using data observations in order to provide recommendations to policy makers. According to the growth rate dynamics, equation (1), i.e., $g_{n+1}{ }^{r *}=\lambda_{g}^{r} g^{r}-\delta_{n}^{r} d^{r}$, we conducted numerical applications in order to study the growth dynamics when corona virus has an impact on the economic growth rate. Taking the growth rates, $\left(g_{n}^{r}\right)$, provided 
by data observations (Source: The World Bank, 2019), the other are provided through calculus on the basis of real data on both virus detections' number and deaths' number for a fixed $n=2019$. Determining the parameters, $\left(\lambda_{g}{ }^{r}\right)_{r=H, E, D}$, knowledge spillovers create growth increasing returns and it helps to determine the importance of each country's growth rate in the sample. Equivalently, the death severity in the sample, $\left(\delta_{n}{ }^{r}\right)_{r=D, E, H}$, is the percentage of severity of the virus in a given country of the data observations sample. Finally, the percentage of the virus detections data, $\left(d_{n}^{r}\right)_{r=D, E, H}$, is measured in $1000 \%$, a code used in the population's dilemma (Source: SAS-COV-2 corona virus).

Presentation of the Calculus Results to the Numerical Experiment of Equation (1), i.e., $g_{n+1}^{r}=\lambda_{g}^{r} g^{r}-\delta_{n}^{r} d^{r}$.

\begin{tabular}{|c|c|c|c|c|c|c|}
\hline & & & & $\lambda_{g}^{H}$ & $\delta_{n}{ }^{H}$ & $g_{n+1}{ }^{H}$ \\
\hline H countries & $\mathrm{vC}_{\mathrm{t}}$ & $\mathrm{D}_{\mathrm{t}}$ & $\mathrm{g}_{\mathrm{n}} \mathrm{n}$ & 0,172 & 0,172 & 0,172 \\
\hline USA & 4233923 & 146935 & $\begin{array}{l}2,3 \\
1,3\end{array}$ & 0,098 & 0,098 & 0,098 \\
\hline RUSSIA & 811073 & 13249 & 14 & 0,105 & 0,105 & 0,105 \\
\hline UK & 301020 & 45837 & 20 & 0,15 & 0,15 & 0,15 \\
\hline Spain & 272421 & 28752 & 03 & 0,02 & 0,02 & 0,02 \\
\hline Italia & 246118 & 35107 & $\begin{array}{l}1,5 \\
0,6\end{array}$ & 0,113 & 0,113 & 0,113 \\
\hline France & 217801 & 30222 & 1,4 & 0,045 & 0,045 & 0,045 \\
\hline Germany & 206667 & 9124 & 1,8 & 0,105 & 0,105 & 0,105 \\
\hline Belgium & 66026 & 9821 & $\begin{array}{l}0,7 \\
13\end{array}$ & 0,545 & 0,545 & 0,545 \\
\hline Netherlands & 53005 & 6159 & 3 & 0,052 & 0,052 & 0,052 \\
\hline Japan & 30548 & 998 & & 1 & 1 & \\
\hline Somme & 6438602 & 326204 & & & & \\
\hline $\begin{array}{c}\mathbf{E} \\
\text { Countries }\end{array}$ & $\mathrm{vc}_{\mathrm{t}}$ & $\mathrm{D}_{\mathrm{t}}$ & $g_{n}^{E}$ & $\lambda_{g}^{E}$ & $\delta_{n}{ }^{H}$ & $g_{n+1}{ }^{E}$ \\
\hline Brazil & 2419091 & 87004 & 1,1 & 0,0364234 & 0,446634 & 0,1537544 \\
\hline India & 1435616 & 32771 & 5 & 0,1655621 & 0,265055 & 0,7844897 \\
\hline South A & 445433 & 6769 & 0,2 & 0,0066222 & 0,082238 & 0,0014522 \\
\hline Mexico & 390516 & 43680 & 0,1 & 0,0033116 & 0,072101 & 0,0153772 \\
\hline Peru & 375961 & 17843 & 2,2 & 0,0728478 & 0,069413 & 0,1540879 \\
\hline Argentina & 162526 & 2939 & 2,2 & 0,0728478 & 0,030003 & 0,1598252 \\
\hline Indonesia & 98778 & 4781 & 5 & 0,1655621 & 0,018239 & 0,8273797 \\
\hline China & 86570 & 4652 & 6,1 & 0,2019865 & 0,015984 & 1,2317484 \\
\hline Angola & 932 & 40 & 7,6 & 0,2516553 & 0,000177 & 1,9125825 \\
\hline Jamaica & 842 & 10 & 0,7 & 0,02317881 & 0,000156 & 0,0162256 \\
\hline SOMME & 5416265 & 200489 & 30,2 & 1 & & \\
\hline
\end{tabular}




\begin{tabular}{|c|c|c|c|c|c|c|}
\hline $\begin{array}{c}\text { D } \\
\text { Countries } \\
\text { Burkina } \\
\text { Tchad } \\
\text { Jamaica } \\
\text { Burundi } \\
\text { Gambia } \\
\text { Erythrea } \\
\text { Haiti } \\
\text { Botwana } \\
\text { Guinée } \\
\text { Congo } \\
\text { SOMME }\end{array}$ & $\begin{array}{c}\mathrm{VC} \mathrm{t}_{\mathrm{t}} \\
1950 \\
915 \\
842 \\
361 \\
277 \\
263 \\
8684 \\
314 \\
10548 \\
5005 \\
29159\end{array}$ & $\begin{array}{c}\mathrm{D}_{\mathrm{t}} \\
56 \\
75 \\
10 \\
1 \\
6 \\
1 \\
227 \\
1 \\
66 \\
89 \\
532\end{array}$ & $\begin{array}{c}\mathrm{g}_{\mathrm{n}}^{\mathrm{D}} \\
6 \\
3,2 \\
0,7 \\
1,8 \\
6 \\
8,7 \\
-2,6 \\
3 \\
5,4 \\
3,8 \\
24,367\end{array}$ & $\begin{array}{c}\lambda_{g}{ }^{D i} \\
0,16666 \\
0,0888 \\
0,0194 \\
0,05 \\
0,1666 \\
0,2416 \\
0,0722 \\
0,0833 \\
0,15\end{array}$ & $\begin{array}{c}\delta_{n}^{D, i} \\
0,06472 \\
0,03137 \\
0,02887 \\
0,01238 \\
0,00949 \\
0,00995 \\
0,29781 \\
0,01076 \\
0,36174\end{array}$ & $\begin{array}{c}g_{n+1} D \\
0,99296 \\
0,28002 \\
0,01306 \\
0,08997 \\
0,99989 \\
2,10248 \\
0,06070 \\
0,24997 \\
0,76512 \\
0,37239\end{array}$ \\
\hline
\end{tabular}

The Social Planner Numerical Experiment Results

\begin{tabular}{|c|c|c|c|c|}
\hline H countries & $\mathrm{y}(\mathrm{H}, \mathrm{t})$ & $\mathrm{y}_{\mathrm{H}}^{\mathrm{t}}$ in $\%$ & $\partial_{\mathrm{H}}^{\mathrm{t}} / \partial \mathrm{t}$ & $\mathrm{y}(\mathrm{H}, \mathrm{t}+1)$ \\
USA & 65760 & 0,0510613 & 3357,79104 & 69117,791 \\
Russia & 11585 & 0,32007336 & 3708,04992 & 15293,0499 \\
UK & 42370 & 0,09963252 & 4221,43004 & 46591,43 \\
Spain & 30390 & 0,22690874 & 6895,75651 & 37285,7565 \\
Italia & 34460 & 0,02787512 & 960,576794 & 35420,5768 \\
France & 42400 & 0,16190391 & 6864,72583 & 49264,7258 \\
Germany & 48520 & 0,21451381 & 10408,21 & 58928,21 \\
Belgium & 47350 & 0,46500927 & 22018,1887 & 69368,1887 \\
Netherlands & 53200 & 0,95334827 & 50718,128 & 103918,128 \\
Japan & 41690 & 2,28800401 & 95386,8871 & 137076,887 \\
\hline
\end{tabular}

Source: Author computations of future income (the theory) through data observations on per-capita income of the World Bank, 2019 and corona virus deaths rates of SARS-COV2

\begin{tabular}{|c|c|c|c|c|}
\hline D & $\mathrm{y}(\mathrm{D}, \mathrm{t})$ & $\mathrm{y}(\mathrm{D}, \mathrm{t})$ in $\%$ & $\mathrm{~d} \mathrm{y}(\mathrm{D}, \mathrm{t}) / \mathrm{dt}$ & $\mathrm{y}(\mathrm{D}, \mathrm{t}+1)$ \\
Countries & 774,8 & 0,03890593 & 15429909,6 & 739,644318 \\
Burkina & 709,5 & 0,03562695 & 709,5 & 734,77732 \\
Tchad & 2658,3 & 0,28031052 & 5582,3 & 5655,51711 \\
Jamaica & 751,3 & 0,01311594 & 261,2 & 271,054005 \\
Burundi & 660 & 0,0377259 & 50,2429782 & 776,199095 \\
Gambia & 754,6 & 0,03314135 & 20,7105868 & 685,008461 \\
Erythrea & & 0,03789161 & 21,7899516 & 790,597027 \\
Haiti & 950 & 0,38464049 & 94,833842 & 8433,55049 \\
Botwana & & 0,04770346 & 9,02465791 & 1216,295 \\
Guinée & & 0,10098068 & 18,1382421 & 2011,10098 \\
& & & & \\
\hline
\end{tabular}


Therefore, the results show only present, current, and future growth rate. Nonetheless, the first doesn't incorporate the corona virus, since they are from 2019, and the sudden shock emergence is around January 2020 (see Figure 1 for presentation of the corona virus emergence). 